\title{
Generation of Novel Anti-MUC1 Monoclonal Antibodies with Designed Carbohydrate Specificities Using MUC1 Glycopeptide Library
}

Shoichi Naito, ${ }^{\dagger}$ Tatsuya Takahashi, ${ }^{\dagger}$ Junji Onoda, ${ }^{\dagger}$ Shoko Uemura, ${ }^{\dagger}$ Naoki Ohyabu, ${ }^{\dagger}$ Hiroshi Takemoto, ${ }^{\dagger}$ Shoji Yamane, ${ }^{\dagger}$ Ikuo Fujii, ${ }^{\ddagger}$ Shin-Ichiro Nishimura, ${ }^{\S(0)}$ and Yoshito Numata ${ }^{*},{ }^{\dagger}$

\author{
${ }^{\dagger}$ Shionogi Pharmaceutical Research Center, Shionogi \& Co., Ltd., 3-1-1 Futaba-cho, Toyonaka, Osaka 561-0825, Japan \\ ${ }^{\ddagger}$ School of Science, Osaka Prefecture University, 1-1 Gakuen-cho, Naka-ku, Sakai, Osaka 599-8531, Japan \\ ${ }^{\S}$ Faculty of Advanced Life Science, Hokkaido University, N21, W11, Kita-ku, Sapporo, Hokkaido 001-0021, Japan
}

\section{Supporting Information}

ABSTRACT: Numerous anti-mucin 1 (anti-MUC1) antibodies that recognize $O$-glycan core structures have already been developed. However, most of them show low specificities toward $\mathrm{O}$-glycan structures and/or low affinity toward a monovalent epitope. In this study, using an MUC1 glycopeptide library, we established two novel anti-MUC1 monoclonal antibodies (1B2 and 12D10) with designed carbohydrate specificities. Compared with previously reported anti-MUC1 antibodies, 1B2 and 12D10 showed quite different features regarding their specificities, affinities, and reactivity profiles to various cell lines. Both antibodies recognized specific $O$-glycan structures at the $\mathrm{PDT}^{*} \mathrm{R}$ motif (the asterisk represents an $O$-glycosylation site). 1B2 recognized $O$-glycans

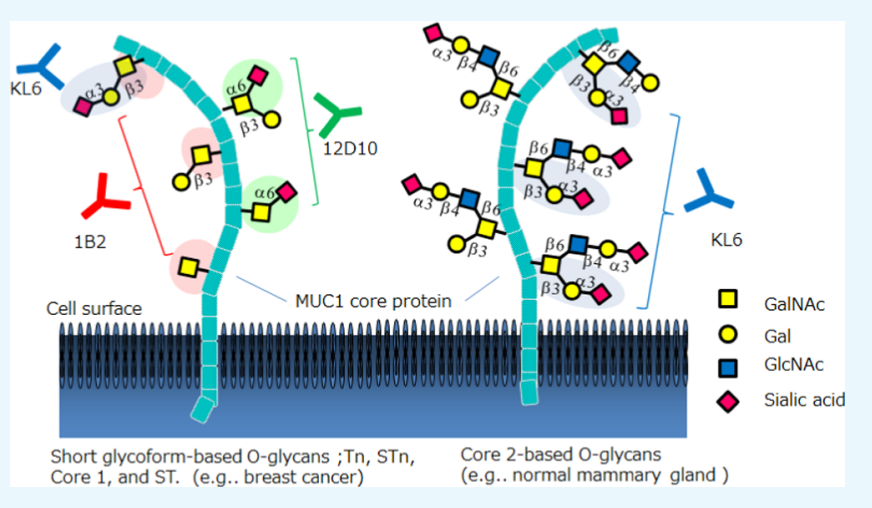
with an unsubstituted O-6 position of the GalNAc residue (Tn, T, and 23ST), whereas 12D10 recognized Neu5Ac at the same position (STn, 26ST, and dST). Neither of them bound to glycopeptides with core 2 O-glycans that have GlcNAc at the O-6 position of the GalNAc residue. Furthermore, 1B2 and 12D10 showed a strong binding to not only native MUC1 but also 20mer glycopeptide with a monovalent epitope. These anti-MUC1 antibodies should thus become powerful tools for biological studies on MUC1 O-glycan structures. Furthermore, the strategy of using glycopeptide libraries should enable the development of novel antibodies with predesigned $O$-glycan specificities.

\section{INTRODUCTION}

Mucin 1 (MUC1) is a high-molecular-weight membraneassociated glycoprotein. The extracellular domain of MUC1 includes a variable number of 20 -amino-acid tandem repeats and high-density $\mathrm{O}$-glycosylation. MUC1 is expressed on the surface of the apical site of normal epithelial cells. In tumor cells, several changes of MUC1 occur. For example, in these cells, MUC1 is expressed all over the cell surface, exhibits increased expression, and its glycosylation pattern also changes. ${ }^{1,2}$ Previously, O-glycan profiles of MUC1 were analyzed using human milk and tumor tissue, ${ }^{3}$ advanced breast cancer patients' serum, ${ }^{4}$ and normal breast epithelial cell lines and breast carcinoma cell lines. ${ }^{5,6}$ The obtained results showed that breast cancer cells had a lower level of core $2 \mathrm{O}$-glycans of MUC1 than normal breast epithelial cells. Conversely, glycans with Neu5Ac or an unsubstituted state at the O-6 position of the GalNAc residue were expressed at higher levels in breast cancer cells than in normal breast epithelial cells.

To study MUC1 glycosylation, monoclonal antibodies (mAbs) that have high specificity for $O$-glycan structures are powerful tools. Indeed, many anti-MUC1 antibodies have already been established. For example, human milk fat globule 1 (HMFG1), ${ }^{7}$ PankoMab, ${ }^{8}$ VU-2G7, ${ }^{9}$ and KL- $6{ }^{10}$ were produced using human mammary milk fat globule, desialylated MUC1 from human breast cancer, MUC1 glycopeptide, and human lung adenocarcinoma as antigens, respectively. Thus, cells, mucins, and synthesized glycopeptides were used as the antigens of MUC1 antibodies. Several anti-MUC1 antibodies recognized not only the core peptide but also O-glycans. More than 10 years ago, it was difficult to determine the precise carbohydrate epitopes that the anti-MUC1 antibodies recognized. In our previous study, an MUC1 glycopeptide library was developed; using this library, we elucidated the PDT*R motif with a 23ST carbohydrate structure to be epitope of the antiMUC1 antibody KL-6. ${ }^{11}$ Another anti-MUC1 antibody 5E5 also showed the glycan-peptide specificity (Tn and STn at the $\mathrm{GST}^{*} \mathrm{~A}$ region). ${ }^{12}$ In addition, high-throughput analysis of glycan specificities using a glycan microarray has been

Received: May 31, 2017

Accepted: October 9, 2017

Published: November 1, 2017 

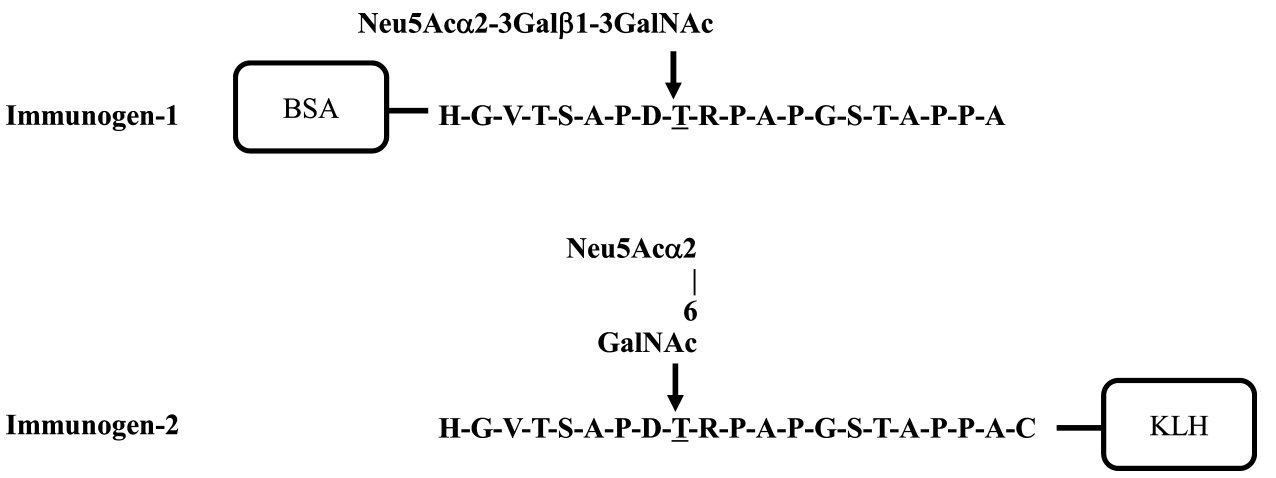

Figure 1. Immunogens for anti-MUC1 monoclonal antibodies. Immunogen-1 is PDT*R-23ST-20-mer conjugated with BSA and designed for antibodies that recognize $O$-glycans with an unsubstituted O-6 position of the GalNAc residue (Tn, T, and 23ST). Immunogen-2 is PDT*R-STn-20mer conjugated with KLH and designed for antibodies that recognize Neu5Ac residue at the O-6 position of GalNAc residue (STn, 26ST, and dST).

Table 1. Summary of MUC1 Glycopeptides Used in This Study ${ }^{a}$

\begin{tabular}{|c|c|c|c|}
\hline No. & Name & $\begin{array}{c}\text { MUC1 core peptide } \\
(\text { glycosylation sites are represented by } *)\end{array}$ & Glycan \\
\hline 1 & PDT*R-Tn-20-mer & HGVTSAPDT*RPAPGSTAPPA & GalNAc $\alpha 1$ \\
\hline 2 & PDT*R-T-20-mer & HGVTSAPDT*RPAPGSTAPPA & Gal $\beta 1-3$ GalNAc $\alpha 1$ \\
\hline 3 & PDT*R-23ST-20-mer & HGVTSAPDT $*$ RPAPGSTAPPA & Neu5Ac $\alpha 2-3$ Gal $\beta 1-3$ GalNAc $\alpha 1$ \\
\hline 4 & PDT*R-STn-20-mer & HGVTSAPDT $*$ RPAPGSTAPPA & Neu5Ac $\alpha 2-6$ GalNAc $\alpha 1$ \\
\hline 5 & PDT*R-26ST-20-mer & HGVTSAPDT $*$ RPAPGSTAPPA & Gal $\beta 1-3[$ Neu5Ac $\alpha 2-6]$ GalNAc $\alpha 1$ \\
\hline 6 & PDT*R-dST-20-mer & HGVTSAPDT $*$ RPAPGSTAPPA & Neu5Ac $\alpha 2-3$ Gal $\beta 1-3[$ Neu5Ac $\alpha 2-6]$ GalNAc $\alpha 1$ \\
\hline 8 & PDT*R-23ST6L-20-mer & HGVTSAPDT*RPAPGSTAPPA & Neu5Ac $\alpha 2-3 \mathrm{Gal} \beta 1-3[\mathrm{Gal} \beta 1-4 \mathrm{GlcNAc} \beta 1-6] \mathrm{GalNAc} \alpha 1$ \\
\hline 9 & PDT*R-23ST6SL-20-mer & HGVTSAPDT*RPAPGSTAPPA & Neu5Ac $\alpha 2-3 \mathrm{Gal} \beta 1-3[\mathrm{Neu} 5 \mathrm{Ac} \alpha 2-3 \mathrm{Gal} \beta 1-4 \mathrm{GlcNAc} \beta 1-6] \mathrm{GalNAc} \alpha 1$ \\
\hline 10 & GVT*S-23ST-20-mer & HGVT*SAPDTRPAPGSTAPPA & Neu5Ac $\alpha 2-3$ Gal $\beta 1-3$ GalNAc $\alpha 1$ \\
\hline 11 & GVT*S-STn-20-mer & HGVT*SAPDTRPAPGSTAPPA & Neu5Ac $\alpha 2-6$ GalNAc $\alpha 1$ \\
\hline 12 & PDT*R-23ST-40-mer & {$[\text { HGVTSAPDT*RPAPGSTAPPA }]_{2}$} & Neu5Ac $\alpha 2-3 \mathrm{Gal} \beta 1-3 \mathrm{GalNAc} \alpha 1$ \\
\hline 13 & PDT*R-23ST-60-mer & {$[\text { HGVTSAPDT } * \text { RPAPGSTAPPA }]_{3}$} & Neu5Ac $\alpha 2-3$ Gal $\beta 1-3$ GalNAc $\alpha 1$ \\
\hline 14 & PDT*R-23ST-100-mer & {$[\text { HGVTSAPDT } * \text { RPAPGSTAPPA }]_{5}$} & Neu5Ac $\alpha 2-3$ Gal $\beta 1-3$ GalNAc $\alpha 1$ \\
\hline 16 & PDT*R-STn-60-mer & {$[\text { HGVTSAPDT } * \text { RPAPGSTAPPA }]_{3}$} & Neu5Ac $\alpha 2-6$ GalNAc $\alpha 1$ \\
\hline 17 & PDT*R-STn-100-mer & [HGVTSAPDT*RPAPGSTAPPA $]_{5}$ & Neu5Ac $\alpha 2-6$ GalNAc $\alpha 1$ \\
\hline 18 & MUC1 peptide 40 -mer & {$[\text { HGVTSAPDTRPAPGSTAPPA }]_{2}$} & -- \\
\hline
\end{tabular}

${ }^{a}$ An asterisk represents amino acids with an attached glycan.

developed in recent years ${ }^{13-15}$ and applied to the analysis of the epitopes of various anti-MUC1 antibodies. The binding analysis of anti-Tn monoclonal antibodies with the array of synthetic saccharides and glycopeptides determined the detailed glycan specificities. ${ }^{16}$ However, most of them did not have apparent glycan specificities. Furthermore, they showed tandem-repeatdependent binding and weak binding to monovalent epitopes, despite being strongly bound to the antigen with multivalent epitopes. ${ }^{17}$ As a reason for these characteristics, it was considered that most of the previously reported anti-MUC1 antibodies were produced using the cells or mucin glycoproteins as antigens, which include various glycan structures. In some cases, synthesized MUC1 glycopeptides were used as antigens, ${ }^{12}$ but anti-MUC1 antibodies with wellpredesigned glycan specificity have not been reported.

To overcome the problems associated with this, in this study, we generated two novel anti-MUC1 antibodies with predesigned epitopes using synthesized MUC1 glycopeptides as antigens and an MUC1 glycopeptide library and native MUC1 for antibody screening (Figure 1 and Table 1). To the best of our knowledge, this is the first report describing the generation of antibodies with a predesigned glycan specificity of the core region of $\mathrm{O}$-glycans at the site of attachment in the immunogen and strong affinity to a monovalent epitope as well as tandemrepeating multivalent MUC1 glycoproteins.

\section{RESULTS}

Design of Carbohydrate Specificities for Novel MUC1 Antibodies. Previous studies that have reported on MUC1 Oglycan analysis of various samples derived from breast cancer and normal cells ${ }^{3-6}$ are summarized in Table 2. Figure 2 presents the biosynthetic pathway focused on the glycans at the O-6 position of the GalNAc residue. MUC1 O-glycans of milk serum and a normal breast cell lines contained an abundance of core 2 glycan structures. On the other hand, MUC1 O-glycans of tumor tissue and cancer cell lines contained glycans with no sugar substitution (Tn, T, and 23ST) or Neu5Ac (STn, 26ST, and $\mathrm{dST}$ ) at the $\mathrm{O}-6$ position of the GalNAc residue. We focused on the difference in MUC1 glycans between normal and tumor tissues and attempted to generate two novel antiMUC1 monoclonal antibodies that strictly recognize the glycans at the O-6 position of the GalNAc residue. The criteria for the two novel antibodies are that neither of them recognizes the core 2 structure; one antibody recognizes glycans with an unsubstituted O-6 position of the GalNAc residue (Tn, T, and 
Table 2. Summary of MUC1 O-Glycan Analyses Reported Previously ${ }^{a}$

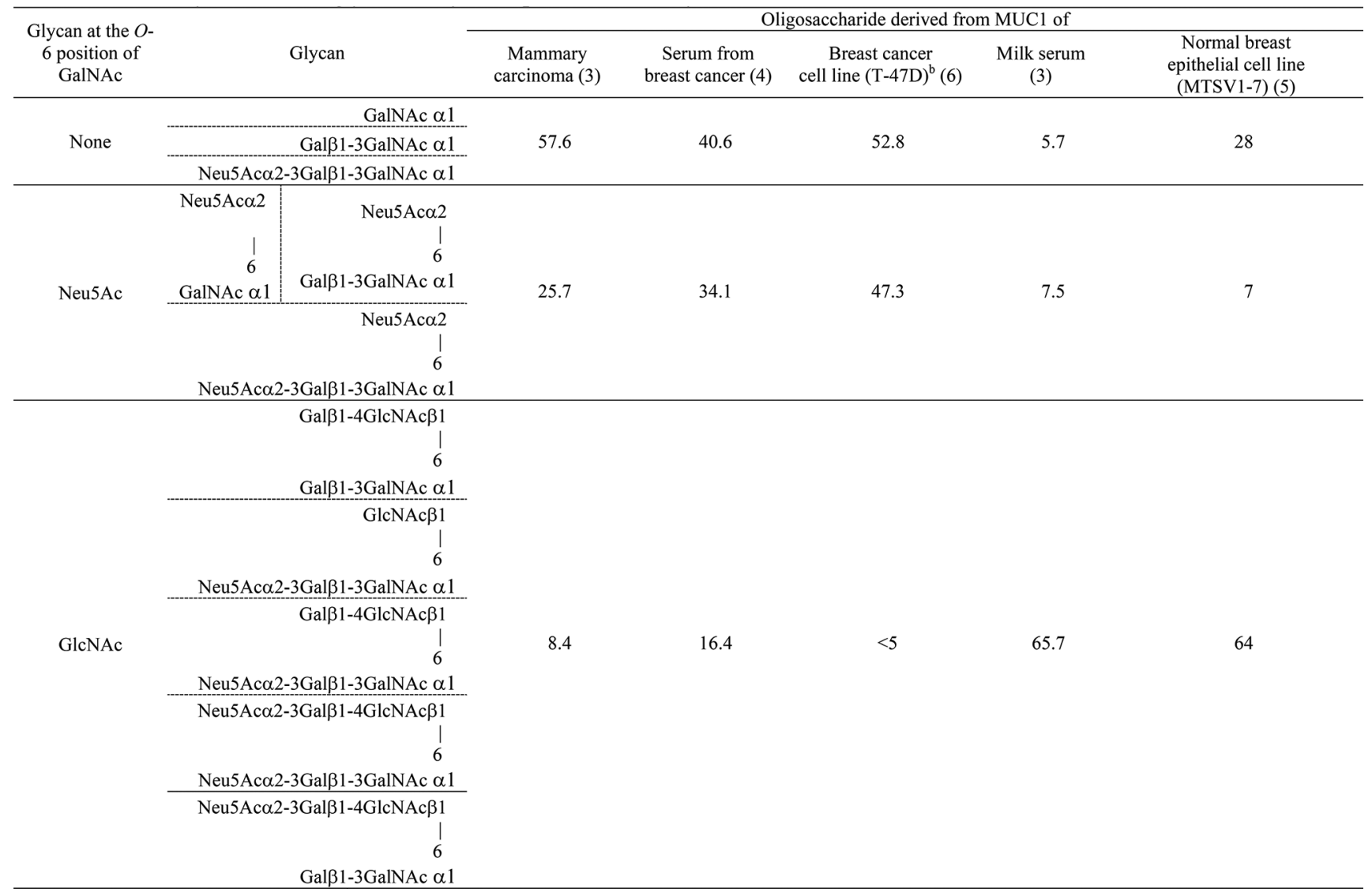

${ }^{a}$ Data are modified from refs $3-6 .{ }^{b} \mathrm{MUC1}$ was expressed as recombinant protein in T-47D cells.

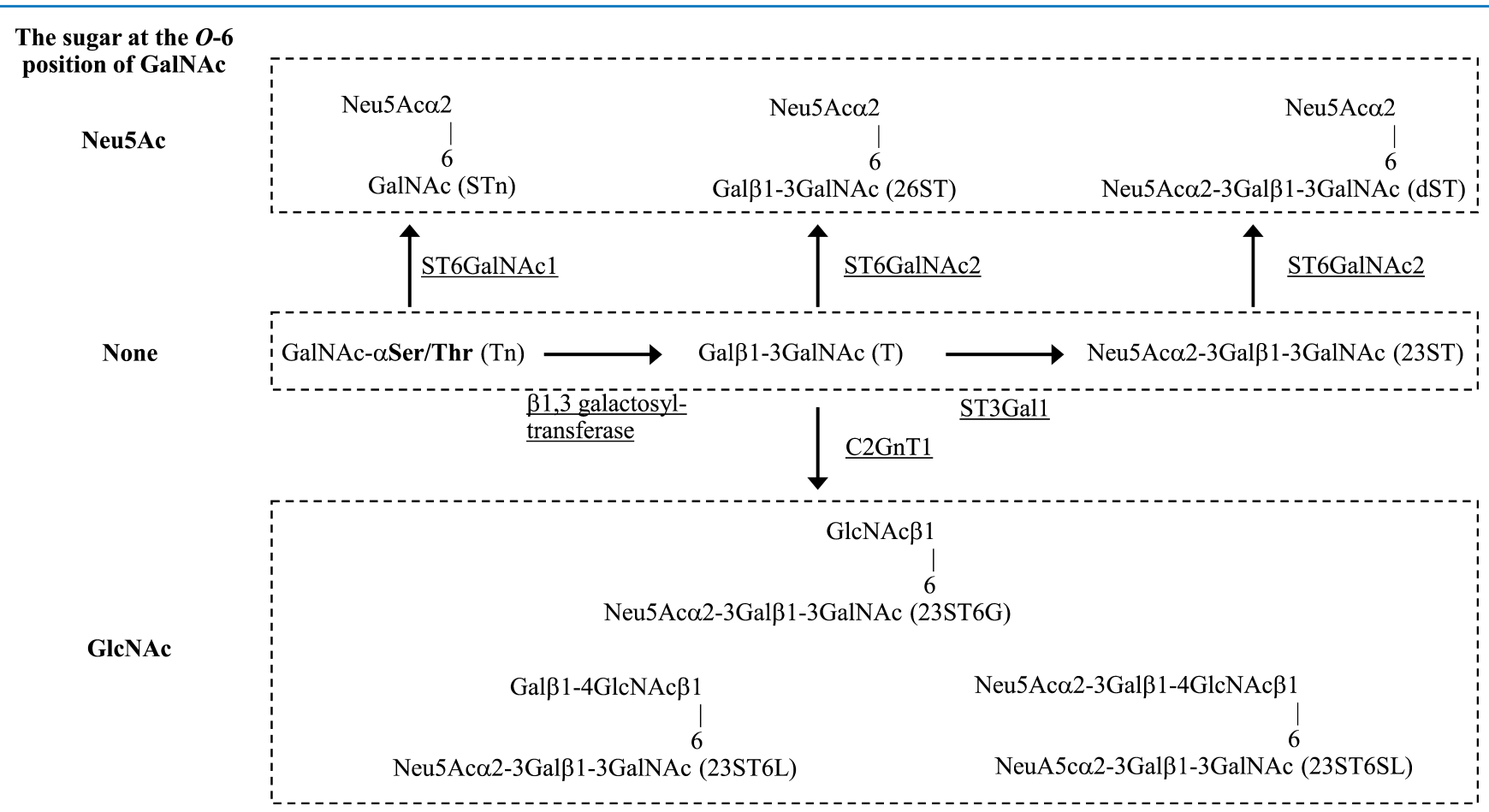

Figure 2. Biosynthetic pathway of $O$-glycans. A schematic representation of the synthesis of $O$-glycans, especially focused on the sugar at the $O-6$ position of the GalNAc residue. O-Glycan structures and glycosyltransferases are indicated.

23ST) and the other antibody recognizes glycans with Neu5Ac at the same position (STn, 26ST, and dST).
The MUC1 core peptide (HGVTSAPDTRPAPGSTAPPA) contains five putative $O$-glycosylation sites. The $\mathrm{PDT}^{*} \mathrm{R}$ region 
Table 3A. Characteristics of Anti-MUC1 Monoclonal Antibodies against PDT*R-23ST-20-mer ${ }^{a}$

\begin{tabular}{|c|c|c|c|c|c|c|}
\hline & \multirow[b]{2}{*}{$\begin{array}{l}\text { Glycosylation } \\
\text { site }\end{array}$} & \multirow[b]{2}{*}{ Glycan } & \multicolumn{4}{|c|}{ Anti-MUC1 antibodies } \\
\hline & & & $1 \mathrm{~B} 2$ & $2 \mathrm{~A} 2$ & $7 \mathrm{~B} 6$ & $13 \mathrm{H} 5$ \\
\hline $\begin{array}{c}\text { Reactivity with } \\
\text { PDT*R-23ST-20-mer }^{\text {b }}\end{array}$ & $\mathrm{PDT}^{*} \mathrm{R}$ & Neu5Ac $\alpha 2-3$ Gal $\beta 1-3$ GalNAc $\alpha 1$ & ++ & + & + & + \\
\hline \multirow{3}{*}{$\begin{array}{l}\text { Cross-reactivity with } \\
\text { PDT*R-23ST6SL-20-mer or } \\
\text { GVT*S-23ST-20-mer }^{c, d}\end{array}$} & & Neu5Ac $\alpha 2-3$ Gal $\beta 1-4 G l c N A c \beta 1$ & & & & \\
\hline & $\mathrm{PDT}^{*} \mathrm{R}$ & $\begin{array}{c}\mid \\
6 \\
\text { Neu5Ac } \alpha 2-3 \text { Gal } \beta 1-3 \text { GalNAc } \alpha 1\end{array}$ & - & - & - & ++ \\
\hline & $\mathrm{VT} * \mathrm{SA}$ & Neu5Ac $\alpha 2-3$ Gal $\beta 1-3$ GalNAc $\alpha 1$ & - & - & + & + \\
\hline $\begin{array}{l}\text { Cross-reactivity with } \\
\text { MUC1 core peptide } \\
\text { c,d }\end{array}$ & & None & - & - & + & + \\
\hline $\begin{array}{c}\text { Reactivity with native MUC1 } \\
\text { of T-47D cell lysate }\end{array}$ & & & ++ & + & ++ & + \\
\hline
\end{tabular}

${ }^{a}$ Reactivities of anti-MUC1 antibodies with immunogen peptide (PDT*R-23ST-20-mer) were assessed by competitive ELISA. The specificities were determined by cross-reactivities against PDT*R-23ST-20-mer. ${ }^{b}++$, Half-maximal inhibitory concentration $\left(\mathrm{IC}_{50}\right)<10 \mathrm{nM} ;+, \mathrm{IC}_{50}<300 \mathrm{nM}$. ${ }^{c}$ Cross-reactivity was determined by competitive ELISA and calculated as follows: $\left(\mathrm{IC}_{50}\right.$ of PDT*R-23ST-20-mer)/(IC $\mathrm{I}_{50}$ of a competitor peptide) $\times$ 100. ${ }^{d}-$, Cross-reactivity $<0.5 \% ;+$, cross-reactivity $<5 \%$; + , cross-reactivity $<50 \%$. ${ }^{e}$ Reactivity was determined by competitive ELISA. ${ }_{+++}$ Dilution factor of T-47D cell lysate at $\mathrm{IC}_{50}>1000 ;+$, dilution factor of $\mathrm{T}-47 \mathrm{D}$ cell lysate at $\mathrm{IC}_{50}>100$.

Table 3B. Characteristics of Anti-MUC1 Monoclonal Antibodies against PDT*R-STn-20-mer ${ }^{a}$

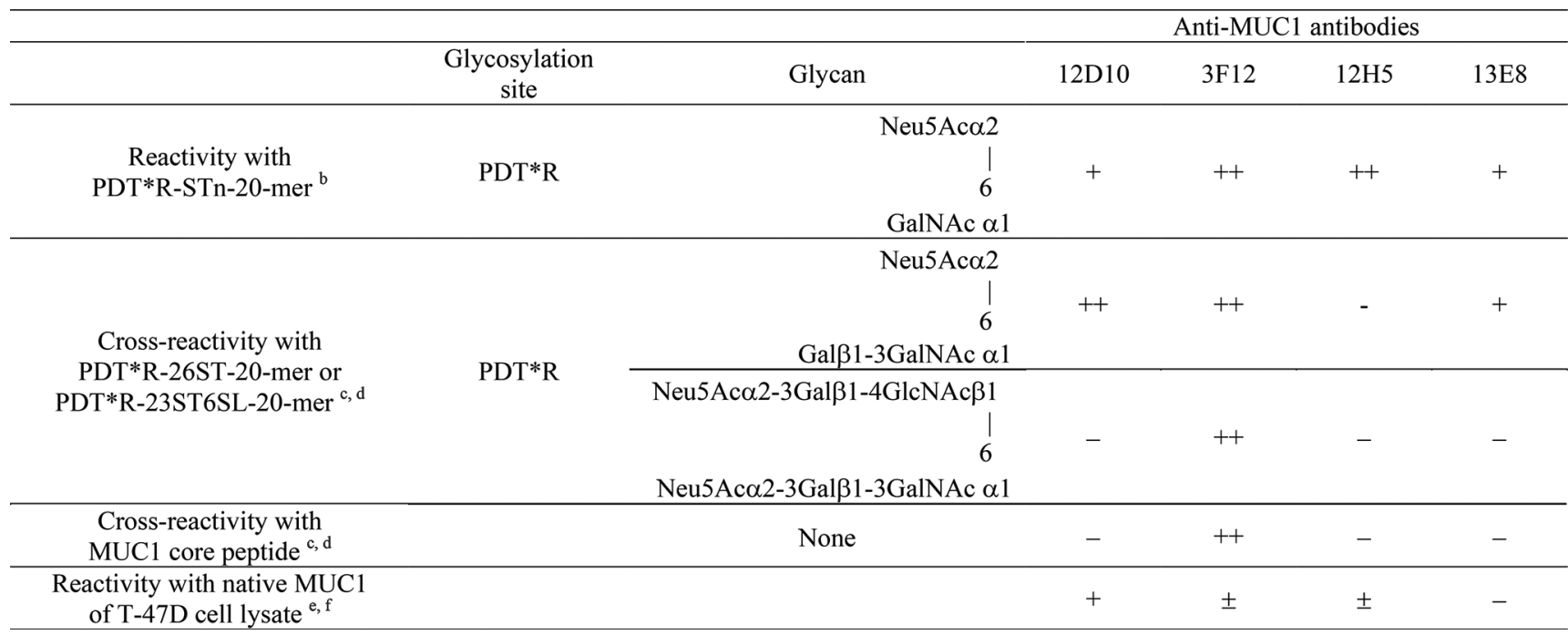

${ }^{a}$ Reactivities of anti-MUC1 antibodies with immunogen peptide (PDT*R-STn-20-mer) were assessed by competitive ELISA. The specificities were determined by cross-reactivities against PDT*R-STn-20-mer. ${ }^{b}++, \mathrm{IC}_{50}<10 \mathrm{nM} ;+, \mathrm{IC}_{50}<100 \mathrm{nM}$. ${ }^{c}$ Cross-reactivity was determined by competitive ELISA and calculated as follows: ( $\mathrm{IC}_{50}$ of PDT*R-STn-20-mer/IC ${ }_{50}$ of a competitor peptide) $\times 100$. $^{d}-$, Cross reactivity $<5 \% ;+$, cross reactivity $<$ $50 \% ;++$, cross reactivity $\geq 50 \% .{ }^{e}$ Reactivity was determined by competitive ELISA. ${ }_{+}$, Dilution factor of T-47D cell lysate at $\mathrm{IC}_{50}>10 ; \pm$, dilution factor of $\mathrm{T}-47 \mathrm{D}$ cell lysate at $\mathrm{IC}_{50} \leq 10 ;-$, no reactivity.

(asterisk indicates a glycosylated amino acid) is known to be immunodominant, and many anti-MUC1 antibodies recognize this region. ${ }^{18}$ In this study, we also focused on this region and designed two types of glycopeptides: PDT*R-23ST-20-mer and PDT*R-STn-20-mer.

Generation of Anti-MUC1 Monoclonal Antibodies. As immunogens, MUC1 glycopeptides (PDT*R-23ST-20-mer and PDT*R-STn-20-mer) were conjugated with carrier proteins, immunogen-1 (PDT*R-23ST-20-mer-bovine serum albumin (BSA) conjugate) and immunogen-2 (PDT*R-STn-20-merkeyhole limpet hemocyanin $(\mathrm{KLH})$ ). To obtain high-affinity antibodies against a monovalent epitope, we performed screening by capture enzyme-linked immunosorbent assay (ELISA) using biotinylated PDT*R-23ST-20-mer or biotinylated PDT*R-STn-20-mer.

Using immunogen-1, we selected four hybridoma clones $(1 \mathrm{~B} 2,2 \mathrm{~A} 2,7 \mathrm{~B} 6$, and $13 \mathrm{H} 5)$ that bound to $\mathrm{PDT}^{*} \mathrm{R}-23 \mathrm{ST}-20$ - mer (Table 3A). Among them, 7B6 and 13H5 bound to the nonglycosylated peptide (MUC1 peptide 40-mer) and did not have designed specificity. The rest of the antibodies (1B2 and 2A2) did not bind PDT*R-23ST6SL-20-mer containing GlcNAc at the $0-6$ position of the GalNAc residue. Furthermore, 1B2 showed a stronger binding to the native MUC1 protein fraction from the breast cancer cell lines ( $T$ 47D) than 2A2. We finally selected $1 B 2$ (IgG2a, kappa) as an anti-MUC1 antibody recognizing glycans with an unsubstituted O-6 position of the GalNAc residue.

In a similar way, anti-MUC1 antibodies recognizing Neu5Ac at the $0-6$ position of the GalNAc residue were selected. Using immunogen-2 (PDT*R-STn-20-mer-KLH conjugate), we selected four hybridoma clones (12D10, 3F12, 12H5, and 13E8) that bound to PDT*R-STn-20-mer (Table 3B). Among them, 3F12 bound the nonglycosylated peptide (MUC1 peptide 40-mer) and did not have designed specificity. The 
Table 4. Glycan Specificities of Anti-MUC1 Monoclonal Antibodies Determined by Competitive ELISA ${ }^{a}$

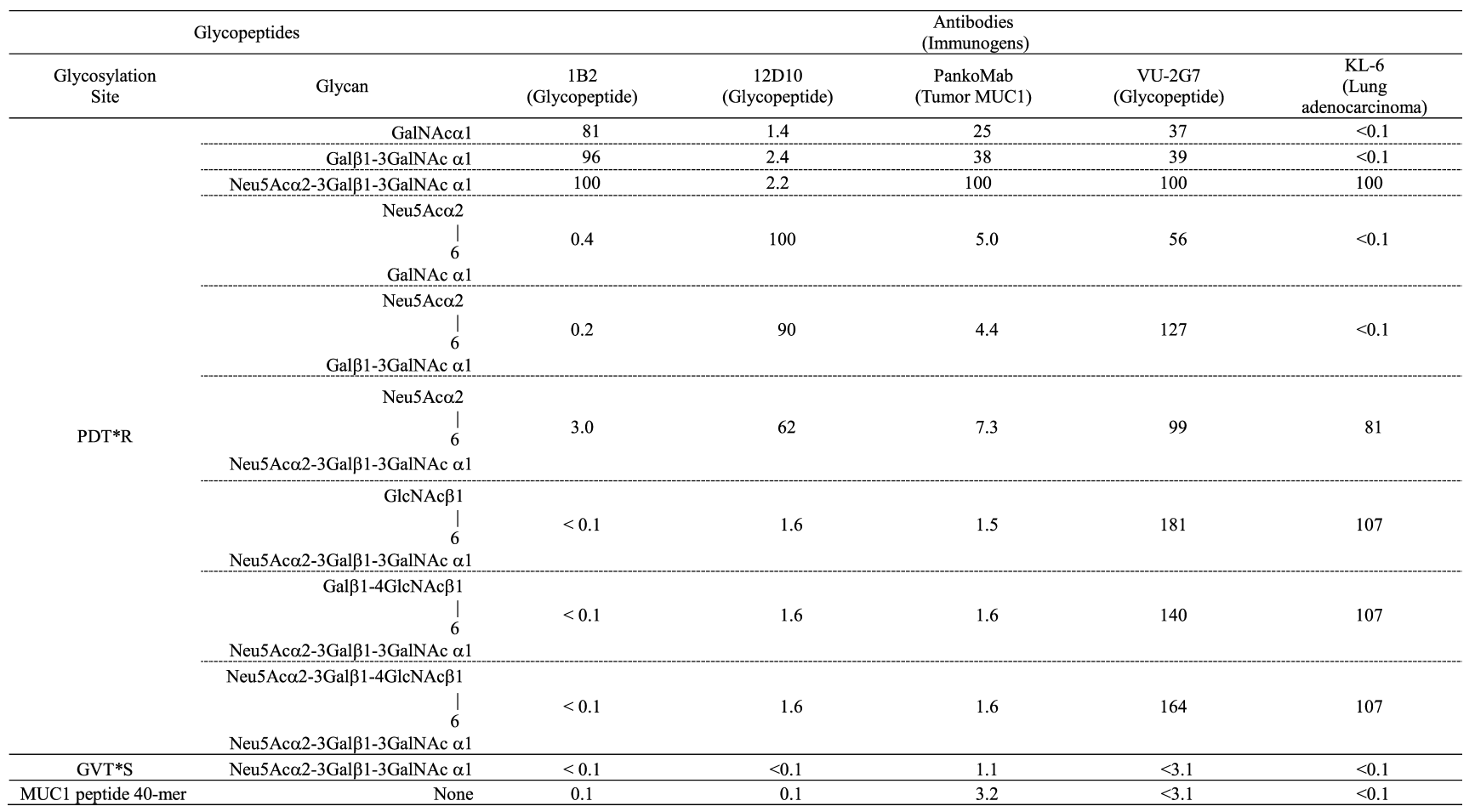

${ }^{a}$ Specificities of anti-MUC1 antibodies are presented as cross-reactivity (\%). Various glycopeptides were used as competitors against PDT*R-23ST20-mer for 1B2, PankoMab, VU-2G7, and KL-6 and against PDT*R-STn-20-mer for 12D10.

Table 5. Binding Affinities of Anti-MUC1 Antibodies

\begin{tabular}{lcccc}
\hline \multicolumn{5}{c}{ (A) $K_{\mathrm{D}}$ Values Measured by Biacore Analysis } \\
\cline { 2 - 5 } & \multicolumn{5}{c}{$K_{\mathrm{D}}[\mathrm{nM}]$} \\
\cline { 2 - 5 } & $1 \mathrm{~B} 2$ & $12 \mathrm{D} 10$ & PankoMab & VU-2G7 \\
\hline PDT*R-Tn-100-mer peptide & 0.4 & 1.7 & 1500 & 180 \\
PDT*R-STn-100-mer peptide & & & 100 & 180 \\
native MUC1 from T-47D & 2.6 & 40 & & \\
\hline
\end{tabular}

\begin{tabular}{lccccc}
\hline \multicolumn{5}{c}{ (B) $\mathrm{IC}_{50}$ Values Determined by Competitive ELISA. } \\
\cline { 2 - 6 } \multicolumn{1}{c}{ immobilized MUC1 } & $1 \mathrm{~B} 2$ & $12 \mathrm{D} 10$ & PankoMab & VU-2G7 & KL-6 \\
\cline { 2 - 6 } & 1.2 & 2.6 & 278 & 1426 & 7.5 \\
\hline $\begin{array}{l}\text { PDT*R-23ST-20-mer peptide } \\
\text { PDT*R-STn-20-mer peptide }\end{array}$ & & & & \\
\hline
\end{tabular}

${ }^{a}$ Biacore analysis of KL-6 was not performed because purified KL-6 was not available.

remaining antibodies (12D10, 12H5, and 13E8) did not bind to either PDT*R-23ST6SL-20-mer containing GlcNAc at the O-6 position of the GalNAc residue or the nonglycosylated peptide (MUC1 peptide 40-mer). Out of these three antibodies, 12D10 showed the strongest binding to the native MUC1 protein fraction from the breast cancer cell lines (T-47D). 12D10 did not bind the glycopeptide (GVT*S-STn-20-mer) that was glycosylated at a different site from $\mathrm{PDT}^{*} \mathrm{R}$ by capture ELISA (Figure S1). We finally selected 12D10 (IgG1, kappa) as an anti-MUC1 antibody recognizing the glycans with Neu5Ac at the $0-6$ position of the GalNAc residue.

Characterization of Novel Anti-MUC1 Antibodies (1B2 and 12D10). The glycan specificities, affinities, and tandemrepeat dependence of $1 \mathrm{~B} 2$ and 12D10 were compared with those of the already-known anti-MUC1 antibodies. The glycan specificity of anti-MUC1 antibodies was assessed in detail by competitive ELISA using the MUC1 glycopeptide library (Table 4 and Figure S2). Both 1B2 and 12D10 recognized the glycans attached to the $\mathrm{PDT}^{*} \mathrm{R}$ motif of the MUC1 peptide. One of these antibodies, 1B2, bound to glycans with an unsubstituted O-6 position of the GalNAc residue ( $\mathrm{Tn}, \mathrm{T}$, and 23ST) but did not bind to glycans in which this position was substituted, such as core 2 glycans or STn. The other antibody, 12D10, bound to glycans with Neu5Ac at the O-6 position of the GalNAc residue (STn, 26ST, and dST) but neither to core 2 glycans nor to glycans with an unsubstituted $0-6$ position of the GalNAc residue. We also investigated the glycan specificity of several previously reported anti-MUC1 antibodies (PankoMab, VU-2G7, and KL-6). VU-2G7 bound to the PDT*R motif with any glycan but did not show obvious glycan specificity. As reported previously, KL-6 bound to the glycans containing 23ST attached to the $\mathrm{PDT}^{*} \mathrm{R}$ motif but did not distinguish between core 1 and core 2. PankoMab recognized the glycans with the unsubstituted $0-6$ position of the GalNAc residue attached to the $\mathrm{PDT}^{*} \mathrm{R}$ motif, as well as $1 \mathrm{~B} 2$. However, PankoMab showed more cross-reactivities with core 2 glycans than 1B2 (Figure S2). 
The binding affinities $\left(K_{\mathrm{D}}\right)$ for synthetic 100-mer glycopeptides or native MUC1 were measured by Biacore. Anti-MUC1 antibodies were injected over glycopeptides or a native MUC1 immobilized sensor chip. The kinetic constants were calculated using a bivalent binding model (Table 5A). For synthetic glycopeptides (PDT*R-Tn-100-mer peptide or PDT*R-STn100-mer peptide), 1B2 and 12D10 showed much higher affinities ( $K_{\mathrm{D}}$ of 0.4 and $1.7 \mathrm{nM}$, respectively) than PankoMab and VU-2G7 $\left(K_{\mathrm{D}}\right.$ of more than $\left.180 \mathrm{nM}\right)$. For native MUC1, $1 \mathrm{~B} 2$ and 12D10 also had higher affinities than the previously reported antibodies. For a monovalent epitope, the affinities of anti-MUC1 antibodies including KL-6 were estimated using the $\mathrm{IC}_{50}$ values from competitive ELISA (Table 5B). 1B2, 12D10, and KL-6 showed a strong binding to monovalent MUC1 glycopeptides ( $\mathrm{IC}_{50}$ of $1.2,2.6$, and $7.5 \mathrm{nM}$, respectively), but PankoMab and VU-2G7 bound more weakly $\left(\mathrm{IC}_{50}\right.$ of more than $280 \mathrm{nM}$ ).

MUC1 contains a tandem repeat of 20 amino acids (HGVTSAPDTRPAPGSTAPPA). Therefore, to investigate the tandem-repeat dependence of the binding of anti-MUC1 antibodies, we synthesized MUC1 glycopeptides with different lengths (PDT*R-Tn-20-, 40-, 60-, and 100-mer and PDT*RSTn-20-, 40-, 60-, and 100-mer) and tested the reactivities of anti-MUC1 antibodies by ELISA. For 100-mer glycopeptides, $1 \mathrm{~B} 2$ and 12D10 demonstrated ELISA signals higher than 1.0 at an antibody concentration of $10 \mathrm{ng} / \mathrm{mL}$, whereas PankoMab and VU-2G7 needed an antibody concentration of more than $500 \mathrm{ng} / \mathrm{mL}$ to obtain the same ELISA signals. Furthermore, PankoMab and VU-2G7 bound in a tandem-repeat-dependent manner because these antibodies showed increased ELISA signals depending on the length of the MUC1 glycopeptides. In contrast, $1 \mathrm{~B} 2$ and $12 \mathrm{D} 10$ bound in a tandem-repeatindependent manner (Figure 3).

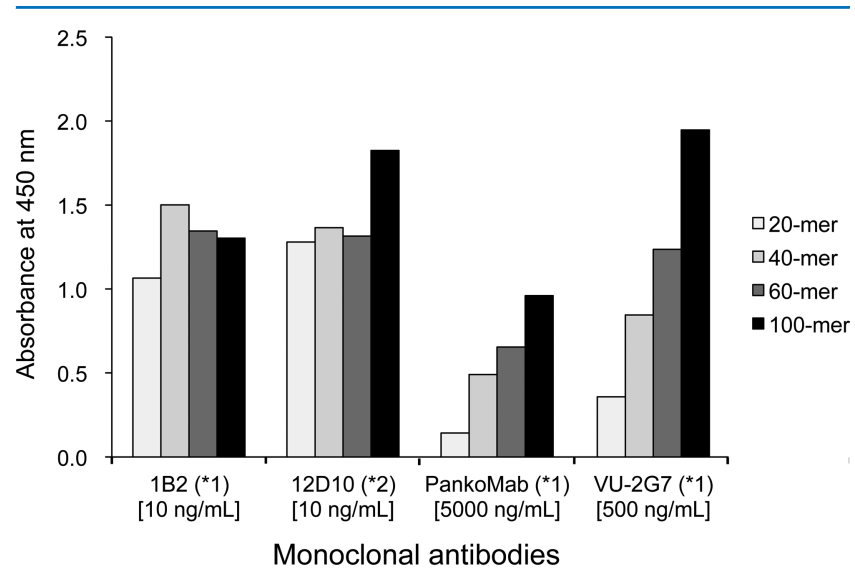

Figure 3. Tandem-repeat dependence of anti-MUC1 monoclonal antibodies. The binding of MUC1 antibodies to MUC1 glycopeptides with different lengths was determined by ELISA. The concentrations of MUC1 antibodies used in ELISA are presented under the graph. ${ }^{*} 1$ : tested using PDT*R-Tn; *2: tested using PDT*R-STn.

Although the tandem-repeat dependence of KL-6 was not investigated, it was suggested that KL- 6 bound strongly to a monovalent epitope because the $\mathrm{IC}_{50}$ of $\mathrm{KL}-6(7.5 \mathrm{nM})$ as determined by competitive ELISA was comparable to that of $1 \mathrm{~B} 2$ and 12D10 (Table 5B).

Comparison of Reactivity of Anti-MUC1 Antibodies to Cell Lines. We investigated the reactivity of anti-MUC1 antibodies to several cell lines and examined its relationship with the expression levels of MUC1 and glycosyltransferases. Five human cell lines were used in this study. These included breast cancer cells (T-47D) and mammary epithelial cells (184A1) derived from human mammary gland, as well as lung adenocarcinoma cells (Calu-3), mucoepidermoid carcinoma cells (H292), and lung adenocarcinoma epithelial cells (A549) derived from human lung.

First, we checked the expression levels of MUC1 protein and messenger RNA (mRNA) (Figure 4). We found correlations between the protein and mRNA expression levels of MUC1. T47D showed the highest expression levels of MUC1 among these five cell lines.

We also investigated the expression levels of glycosyltransferases (C2GnT1, ST6GalNAc1, ST6GalNAc2, and ST3Gal1) in Figure 5. C2GnT1, ST6GalNAc1, and ST6GalNAc2 are important enzymes for the synthesis of branched glycans at the O-6 position of the GalNAc residue. C2GnT1 generates core 2 O-glycans. ST6GalNAc1 and ST6GalNAc2 are involved in the synthesis of STn and 26ST. On the other hand, ST3Gall, which catalyzes the addition of Neu5Ac to the O-3 position of Gal, contributes to the synthesis of 23ST.

C2GnT1 was most highly expressed in 184A1 but hardly expressed in T-47D. The expression levels of ST6GalNAc1 and ST6GalNAc2 varied from cell to cell. ST3Gall was highly expressed in all of the cell lines tested.

The binding of anti-MUC1 antibodies to cell lines was examined using a flow cytometer (Figure 6). PankoMab and VU-2G7 bound only to T-47D, which showed the highest expression level of MUC1, but hardly bound to the other cell lines. This could have been due to the weak affinity of these antibodies, which require multivalent epitopes for strong binding.

In contrast, KL- 6 bound to all of the cell lines. KL-6 strongly bound to monovalent MUC1 glycopeptide containing 23ST regardless of the substitution status at the $0-6$ position of the GalNAc residue. Because the expression levels of ST3Gall were high in all of the cell lines, O-glycans containing the 23ST structure (KL-6-reactive O-glycans) were expected to be abundant in these cell lines.

A novel anti-MUC1 antibody, 1B2, showed a strong binding to T-47D and H292, weak binding to $184 \mathrm{~A} 1$, and no binding to A549. Although the specificity of $1 \mathrm{~B} 2$ was similar to that of PankoMab, the reactivity to $\mathrm{H} 292$ differed between $1 \mathrm{~B} 2$ and PankoMab. The high affinity showed by $1 \mathrm{~B} 2$ to monovalent MUC1 glycopeptide was probably due to the much lower expression level of MUC1 or density of the essential epitope in the MUC1 tandem-repeat in $\mathrm{H} 292$ than that in T-47D.

Another novel anti-MUC1 antibody (12D10) showed strong binding to T-47D and Calu-3, weak binding to H292, and no binding to $184 \mathrm{~A} 1$ and A549. Interestingly, in T-47D and Calu3, the expression levels of ST6GalNAc1 and ST6GalNAc2 were higher than that of C2GnT1 (Table 6). There could be competition between ST6GalNAc and C2GnT1 regarding the synthesis of branched O-glycans at the O-6 position of the GalNAc residue, although the localization of these enzymes in Golgi and the expression level of Cosmc (C1GalT1-specific chaperon) should be also considered. ${ }^{19,20}$ This suggested that the O-glycan structures containing the Neu5Ac at the O-6 position of the GalNAc residue (STn, 26ST, and dST), which are essential for the binding of $12 \mathrm{D} 10$, might be abundant in T47D and Calu-3.

As described above, the characteristics of binding of novel anti-MUC1 antibodies (1B2 and 12D10) to various cell lines 
A

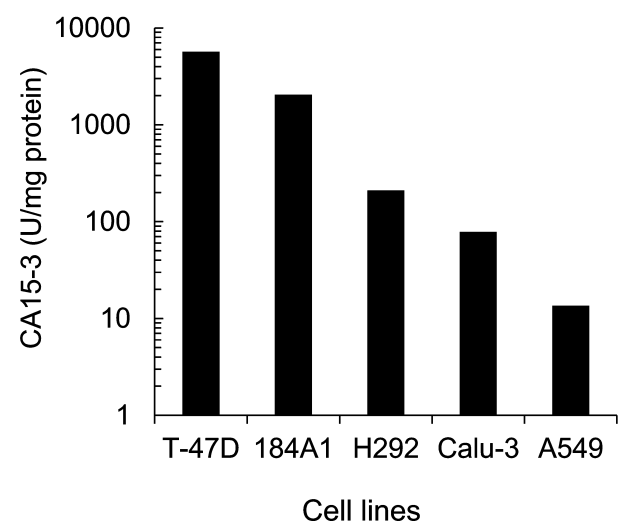

B

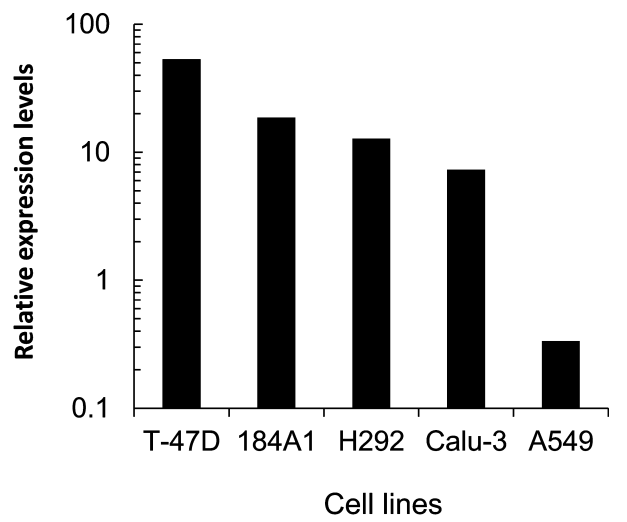

Figure 4. (A) Quantification of MUC1 protein in cell lines was performed using CA15-3 ELISA. CA15-3 is presented as unit per milligram of protein of the cell lines. (B) The mRNA level of MUC1 was determined by reverse transcription polymerase chain reaction (RT-PCR).
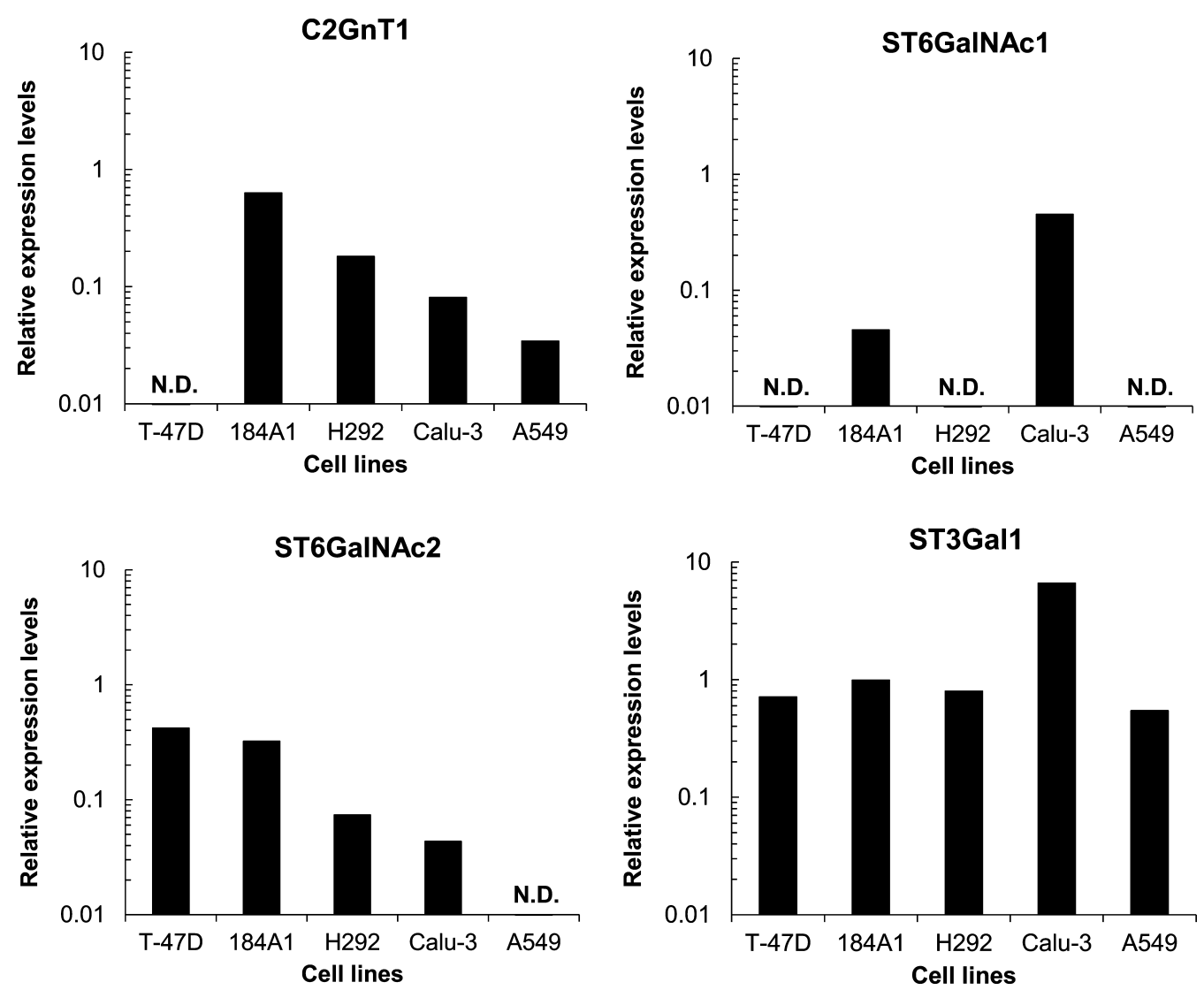

Figure 5. Relative transcript abundance of glycosyltransferases in cell lines was determined by RT-PCR analysis. Data were normalized by the amount of glyceraldehyde 3-phosphate dehydrogenase (GAPDH) mRNA. Relative expression level was less than 0.01; N.D.: not detected.

appeared to be different from those of already-known antiMUC1 antibodies such as PankoMab and VU-2G7.

\section{DISCUSSION}

In $O$-glycan structures, there are various kinds of tumor-related antigens and differentiation antigens, and substantial research about these antigens has been conducted using monoclonal antibodies over the last 30 years. $^{21,22}$ O-Glycan antigens are generally divided into two types. One group (sialyl-Lewis ${ }^{\mathrm{A}}$, Lewis $^{\mathrm{X}}$, and sialyl-Lewis ${ }^{\mathrm{X}}$ ) is located at the nonreducing terminal and commonly located in glycolipids. ${ }^{23,24}$ The other group ( $\mathrm{Tn}, \mathrm{STn}$, and $\mathrm{T}$ ) is located at the core region and unique to $O$-glycans. ${ }^{25,26}$ The study of monoclonal antibodies against glycan antigens on the nonreducing terminal has advanced because the isolation and detection of glycolipids was well developed compared with those of glycoproteins, and isolated glycolipids are useful tools for epitope determination because they retain immunogenicity. ${ }^{27}$ Furthermore, using purified glycolipids or synthesized glycolipids as immunogens, it is possible to obtain anti-glycolipid monoclonal antibodies with a prospectively designed epitope recognition. ${ }^{28}$

However, it has been difficult to generate anti-glycan antibodies that recognize the unique structures at the core region of $\mathrm{O}$-glycans. This is because of the difficulty of purifying 
$1 B 2$

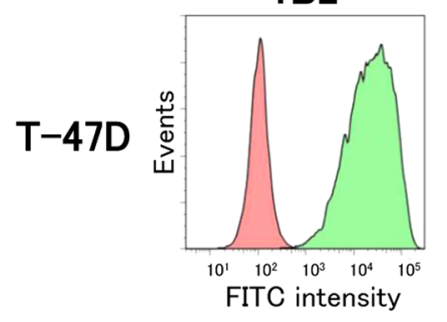

184A1

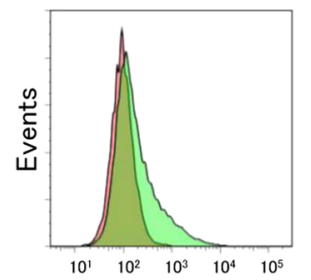

FITC intensity
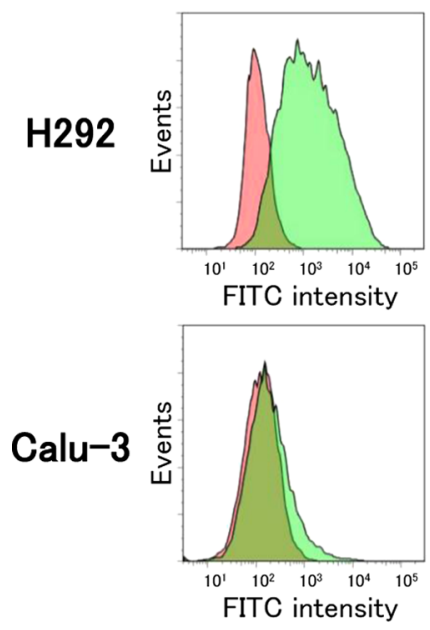

A549

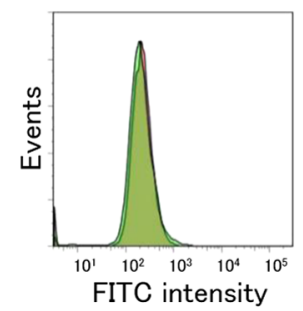

12D10
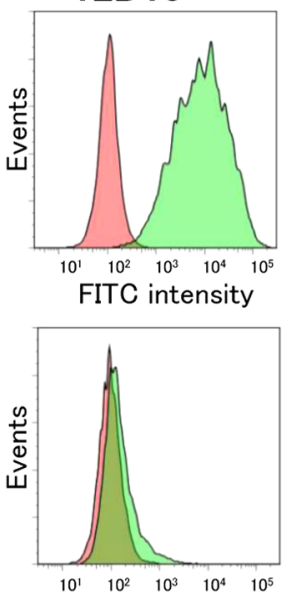

FITC intensity
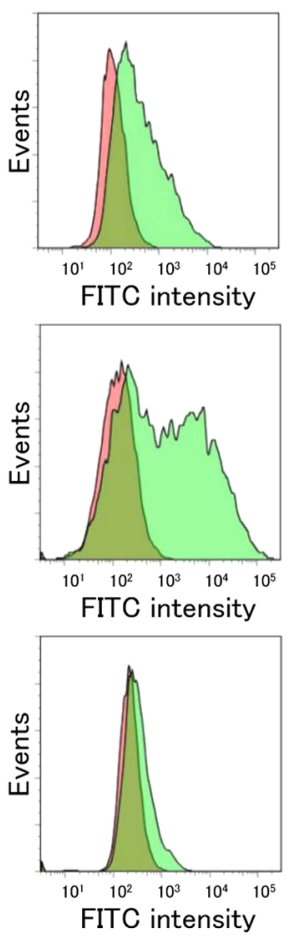
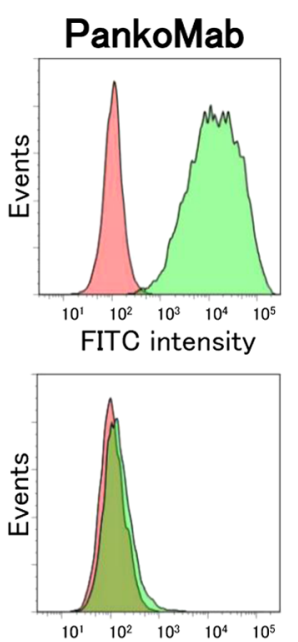

FITC intensity
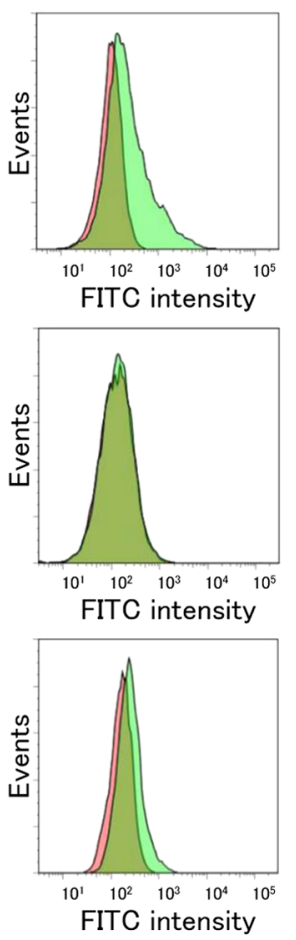
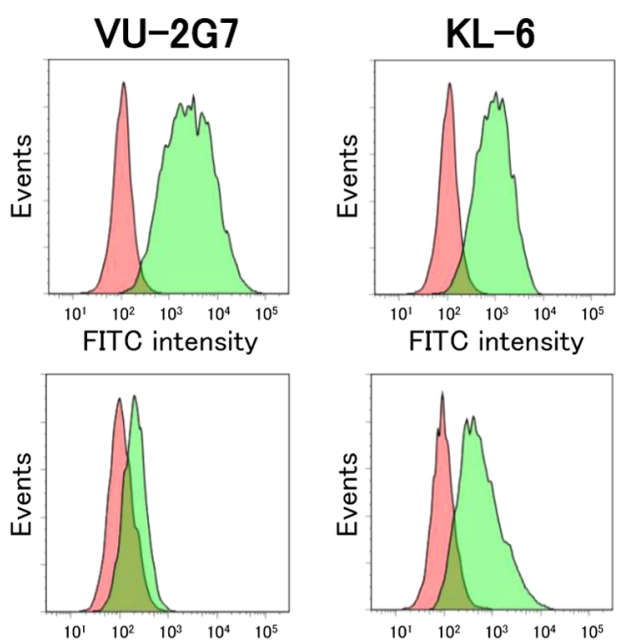

FITC intensity
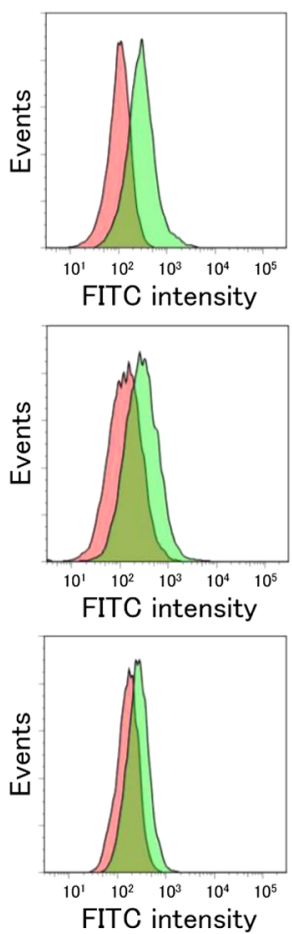

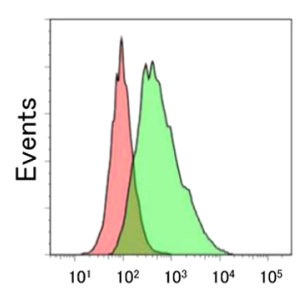

FITC intensity

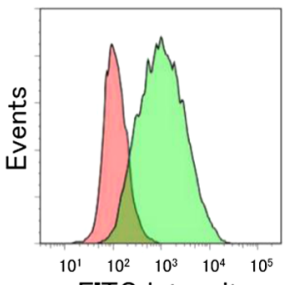

FITC intensity
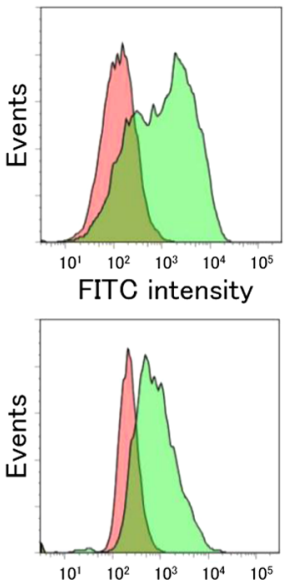

FITC intensity

Figure 6. The binding of MUC1 antibodies to cell lines. Flow cytometric analysis enabled the creation of histograms of MUC1 antibodies binding to cells (filled green), and each histogram was overlaid for comparison with isotype control antibodies (filled magenta).

Table 6. Relationship between Ratio of Glycosyltransferase Expression Levels and Relative Mean Fluorescence Intensity (MFI)

\begin{tabular}{|c|c|c|c|c|c|c|}
\hline \multirow[b]{2}{*}{ cell lines } & \multirow{2}{*}{$\begin{array}{c}\text { ratio of expression levels } \\
\frac{(\mathrm{ST} 6 \mathrm{GalNAc1}+\mathrm{ST} 6 \mathrm{GalNAc2})}{(\mathrm{C} 2 \mathrm{GnT} 1)} \\
\end{array}$} & \multicolumn{5}{|c|}{ relative MFI } \\
\hline & & $1 \mathrm{~B} 2$ & $12 \mathrm{D} 10$ & PankoMab & VU-2G7 & KL-6 \\
\hline T-47D & 88.9 & 297 & 139 & 206 & 42 & 11 \\
\hline $184 \mathrm{~A} 1$ & 0.6 & 4 & 2 & 2 & 2 & 9 \\
\hline H292 & 0.4 & 24 & 7 & 4 & 3 & 14 \\
\hline Calu-3 & 6.1 & 3 & 40 & 1 & 2 & 14 \\
\hline A549 & 0.3 & 1 & 2 & 2 & 2 & 6 \\
\hline
\end{tabular}

O-glycans and the complex epitopes that often contain a peptide portion coupled with $O$-glycans. ${ }^{18,27}$ If $O$-glycans are released from peptides, the immunogenicity is sometimes lost. $^{27}$

Previously, two monoclonal antibodies, MLS102 (anti-STn) and MLS128 (anti-Tn), were raised using colorectal cancer cells (LS 180) as the immunogen. ${ }^{29,30}$ In these previous studies, antibody screening was performed using a solid-phase immunoassay utilizing immobilized glycopeptides prepared from the cells. The epitopes of these antibodies were determined to be ovine submaxillary mucin $(\mathrm{OSM})^{31,32}$ because a large amount of OSM could be prepared for the determination of the epitope. Another group reported monoclonal antibodies (TKH1 and $\mathrm{TKH} 2$ ) directed to $\mathrm{O}$ - 
linked STn epitope by immunizing mouse with OSM. ${ }^{33}$ However, it was generally difficult to reveal the precise epitopes and the specificities of antibodies recognizing both O-glycan and peptide using limited amounts of the naturally occurring glycoproteins having heterogeneous $O$-glycoforms.

To overcome this difficulty, synthetic glycopeptide libraries of MUC1 have recently been developed. ${ }^{34}$ A microarray on which the glycopeptide library is immobilized makes it easier to determine the epitope of MUC1 antibodies in a highthroughput manner. ${ }^{13-16,35}$ To accelerate $O$-glycan research further, it is desirable to generate anti-O-glycan antibodies with prospectively designed specificity in the same way as antiglycolipid antibodies. However, in the past, whole cells and mucins were mostly used as immunogens, ${ }^{7,8}$ so it has been difficult to make antibodies that recognize the core region structure of $O$-glycans with defined specificities. Actually, many anti-MUC1 antibodies recognized the core region structure of $O$-glycans attached to the $\mathrm{PDT}^{*} \mathrm{R}$ motif, but most of them exhibited unclear glycan specificities. VU-2G7, which was established using the glycopeptide PDT*R-Tn-60-mer, required $\mathrm{O}$-glycan attached to $\mathrm{PDT} * \mathrm{R}$ for its binding, but did not have clear specificity (Table 4).

In addition, PankoMab, which was established using desialylated MUC1 as the immunogen, showed specific binding to tumor cells. Clinical trials of PankoMab for the treatment of cancer are now underway. ${ }^{36}$ In our study, PankoMab recognized glycans attached to the $\mathrm{PDT}^{*} \mathrm{R}$ region, especially $O$-glycan with an unsubstituted $0-6$ position of the GalNAc residue. As another example of a known anti-MUC1 antibody, KL-6 was established using human lung adenocarcinoma as immunogen, and its antigen is a useful diagnostic marker of interstitial pneumonia. KL-6 was shown to bind to the glycan containing the 23ST structure in both core 1 and core $2 .{ }^{11}$ The binding of PankoMab and VU-2G7 was found to occur in a tandem-repeat-dependent manner (Figure 3). This might be due to the effect of the avidity because the binding affinities of all of these antibodies were weak against monovalent glycopeptides (Table 5). It was reported that another antiMUC1 monoclonal antibody, SM3, which was generated with a partially deglycosylated MUC1 as an immunogen, recognized PDTR motif. ${ }^{37,38}$ SM3 showed a tumor-specific histological staining pattern. ${ }^{37}$ More interestingly, overexpression of C2GnT1 in T47D cells (normally making core 1-based structures) resulted in the loss of binding of SM3 to MUC1, accompanied by a decrease in the GalNAc/GlcNAc ratio, indicative of a switch to core 2 structures. Therefore, loss of the SM3 binding to MUC1 is apparently due to the core 2 branch masking the polypeptide PDTR motif recognized by SM3. ${ }^{39}$ Thus, SM3 showed interesting features; however, it was also reported that the binding of SM3 was found to occur in a tandem-repeat-dependent manner. ${ }^{17}$ To study the alteration of MUC1 core glycans, it was necessary to establish novel MUC1 antibodies with high specificity and strong affinity for a monovalent glycopeptide epitope distributable in the natural heterogeneous MUC1 glycoprotein. ${ }^{40}$

Using a synthetic MUC1 glycopeptide library, in this study, we produced a new class of MUC1 monoclonal antibodies with prospectively designed specificities. Previously, it was reported that the core 2 glycans decreased in human breast cancer. Therefore, as a model study, we designed two kinds of monoclonal antibodies that do not bind to core 2 glycans. One monoclonal antibody recognizes glycans with an unsubstituted O-6 position of the GalNAc residue ( $\mathrm{Tn}, \mathrm{T}$, and 23ST), whereas the other recognizes glycans with Neu5Ac at the same position (STn, 26ST, and dST); neither of these mAbs binds to core $2 \mathrm{O}$-glycans.

To obtain mAbs with a strong binding affinity toward both glycans and immunodominant peptide structures, several important points should be borne in mind: (a) the monovalent (20-mer) synthetic MUC1 glycopeptides were used as immunogens, (b) the antibody was screened by capture ELISA using biotinylated glycopeptides, and (c) the reactivities not only to glycopeptides but also to native MUC1 were evaluated. After cell fusion, several hybridoma clones that exhibited binding to the immunogen glycopeptides were obtained, but some clones showed a lack of specificity for $O$ glycan structures and/or bound weakly to native MUC1. It has been reported that MUC1 derived from T-47D includes large amounts of short form-based $\mathrm{O}$-glycans (Table 2). Therefore, it was important to test not only $\mathrm{O}$-glycan specificities using synthetic glycopeptides but also binding reactivities using native MUC1 or macromolecular MUC1 models ${ }^{40}$ in the antibodyscreening step for the antibodies with designed glycan specificities.

Finally, we established two novel MUC1 antibodies, 1B2 and 12D10. The epitope of $1 \mathrm{~B} 2$ was found to be similar to that of PankoMab, which recognized core glycans with an unsubstituted O-6 position of the GalNAc residue and did not bind to glycopeptides with core $2 \mathrm{O}$-glycans. However, $1 \mathrm{~B} 2$ showed higher glycan specificity than PankoMab (Figure S2). In addition, the binding of 1B2 occurred in a tandem-repeatindependent manner, which differed from that of PankoMab. The epitope of 12D10 was the core glycans with Neu5Ac at the O-6-position of the GalNAc residue. 12D10 did not bind to the MUC1 glycopeptide with core $2 \mathrm{O}$-glycans. Although numerous MUC1 antibodies have already been studied, no MUC1 antibody with the same glycan specificity as $12 \mathrm{D} 10$ has been reported.

Several anti-MUC1 antibodies that recognize sites other than the $\mathrm{PDT}^{*} \mathrm{R}$ motif have been reported. For example, antiMUC1 antibody (MY.1E12) was obtained using human milk fat globule (HMFG) as an immunogen and shown to recognize GVT*S-23ST. However, its binding affinity was weak ( $K_{\mathrm{D}}$ of $140 \mathrm{nM})$, and its glycan specificity was not fully elucidated. ${ }^{41}$ Another anti-MUC1 antibody (5E5) was obtained using MUC1 60-mer peptides with five GalNAc per tandem repeat (MUC160-Tn15) as an immunogen. This antibody recognized GST*A with Tn or STn, which was not substituted at the O-3 position of the GalNAc residue, and 5E5 was considered to be a tandem-repeat-dependent antibody. ${ }^{12}$

X-ray analysis of glycopeptide and antibody crystal structures $^{42}$ and NMR analysis of glycopeptides ${ }^{43}$ help to know the conformation properties. Both of which can be useful to gain further understanding of the molecular recognition between anti-MUC1 antibodies (1B2 and 12D10) and glycopeptides.

In this study, the reactivities of anti-MUC1 antibodies to several cell lines were examined. Among existing anti-MUC1 antibodies tested, PankoMab and VU-2G7 showed little or no binding to the cell lines with a low expression level of MUC1. This is probably because these antibodies showed low binding affinities to a monovalent glycopeptide epitope.

In contrast, KL-6 with high affinity to a monovalent glycopeptide epitope bound to all of the tested cell lines. KL6 recognized not only core 1 but also core $2 O$-glycans including the 23ST structure. Furthermore, ST3Gal1, which is 
important for the synthesis of 23ST, was highly expressed in all of the cell lines. These features might have contributed to the broad binding profiles of KL-6 against various cell lines.

The novel anti-MUC1 antibodies (1B2 and 12D10) showed different profiles from known anti-MUC1 antibodies (PankoMab, VU-2G7, and KL-6) regarding the reactivities to cell lines. This result reflects the characteristics of $1 \mathrm{~B} 2$ and $12 \mathrm{D} 10$ with high glycan specificity and high affinities to monovalent epitopes. Therefore, it is expected that $1 \mathrm{~B} 2$ and $12 \mathrm{D} 10$ may become useful tools for the biochemical studies of MUC1 Oglycans.

To the best of our knowledge, this is the first report about the generation of antibodies with predesigned glycan specificity of the core region of $\mathrm{O}$-glycans at the site of attachment in the immunogen and strong affinity to a monovalent epitope as well as tandem-repeating multivalent MUC1 glycoproteins. The strategy reported here might also be applicable to the generation of antibodies against $\mathrm{O}$-glycan core structures of various mucin-type glycoproteins other than MUC1. The carbohydrate antigens $\mathrm{Tn}$ and STn are expressed in most carcinomas; however, it has been reported that many important $O$-glycan core structures lack a corresponding antibody, ${ }^{44}$ and there is a need to develop novel antibodies with improved specificities targeting STn or Tn attached at the target immunodominant peptide. ${ }^{45}$ Recently, a combinatory antibody-antigen microarray assay for high-content screening of phage antibodies was reported. ${ }^{46}$ Our strategy also should make it possible to develop novel antibodies against $O$-glycan core structures that could not be obtained by previous approaches using cells or glycoproteins as immunogens.

\section{MATERIALS AND METHODS}

Anti-MUC1 Antibodies. PankoMab (Glycotope, Germany), VU-2G7 (MONOSAN, Netherlands), and KL-6 (EIDIA, Japan) were purchased as reagents. PankoMab and VU-2G7 were used as purified antibodies; however, KL-6 was not available as a purified antibody.

Cell Lines. Human breast cancer cells (T-47D), human lung adenocarcinoma cells (Calu-3), human mucoepidermoid carcinoma cells (H292), and human lung adenocarcinoma epithelial cells (A549) were purchased from American type culture collection (ATCC) and cultured in Dulbecco's modified Eagle's medium (DMEM) supplemented with $10 \%$ fetal bovine serum (FBS) in $5 \% \mathrm{CO}_{2}$ at $37{ }^{\circ} \mathrm{C}$. Human mammary epithelial cells (184A1) were purchased from ATCC and cultured in mammary epithelial cell basal medium supplemented with bovine pituitary extract, epidermal growth factor, insulin, and hydrocortisone in $5 \% \mathrm{CO}_{2}$ at $37{ }^{\circ} \mathrm{C}$.

Preparation of Native MUC1 Fraction from T-47D Supernatant. T-47D was cultured for 3 days in FBS-free medium. The medium was harvested and centrifuged for 10 min at $1000 \mathrm{~g}$ and filtered over $0.22 \mu \mathrm{m}$ bottle-top filters. Then, the medium was changed to $50 \mathrm{mM} \mathrm{N}$-(2-hydroxyethyl)piperazine- $N^{\prime}$-ethanesulfonic acid buffer $(\mathrm{pH} 7.4)$ and concentrated using an Amicon Ultra-15 Centrifugal Filter Unit with Ultracel-100 membrane (Millipore, Germany). Next, the native MUC1 fraction was biotinylated using NHS-PEG4Biotin (Thermo Fisher Scientific, Waltham, MA), in accordance with the manufacturer's instructions.

Synthesis of Glycopeptides. All of the glycopeptides were synthesized as reported previously. ${ }^{11,34,39}$ The glycopeptides used in this study are summarized in Table 1.
Preparation of Immunogen-1 (PDT*R-23ST-20-merBSA Conjugate) To Raise Anti-MUC1 Antibodies Recognizing O-glycans with an Unsubstituted 0-6 Position of the GalNAc Residue. HGVTSAPD (Neu5A$c \alpha 2-3 \mathrm{Gal} \beta 1-3 \mathrm{GalNAc}$ ) TRPAPGSTAPPA (PDT*R-23ST-20mer) was modified by sulfo-SMCC (Thermo Fisher Scientific) to make maleimide-activated glycopeptide. The sulfhydryl groups were introduced to BSA by the reaction with sulfoLC-SPDP (Thermo Fisher Scientific). The sulfhydryl-activated BSA was incubated with the maleimide-activated glycopeptide. The reaction mixture was dialyzed against distilled water and then freeze-dried (immunogen-1: Figure 1).

Preparation of Immunogen-2 (PDT*R-STn-20-merKLH Conjugate) To Raise Anti-MUC1 Antibodies Recognizing O-glycans with Neu5Ac at the 0-6 Position of the GalNAc Residue. HGVTSAPD (Neu5Ac $\alpha 2-6 \mathrm{GalNAc}$ ) TRPAPGSTAPPA (PDT*R-STn-20-mer) was incubated with Imject Maleimide-activated KLH (Thermo Fisher Scientific), in accordance with the manufacturer's instructions. The reaction mixture was dialyzed against distilled water and then freezedried (immunogen-2: Figure 1).

Generation of Anti-MUC1 Antibodies. Female Balb/c, 4-6 week-old mice were injected intraperitoneally with $100 \mu \mathrm{g}$ of the immunogen emulsified in complete Freund's adjuvant (Difco, Franklin Lakes, NJ). The immunization was repeated with the immunogen emulsified in incomplete Freund's adjuvant three times at 3 week intervals.

Hybridomas were generated by fusing the spleen cells with P3U1 murine myeloma cells following the standard protocol. The hybridomas were cultured in medium containing hypoxanthine/aminopterin/thymidine. Supernatants were collected from the cloned hybridoma cultures and examined for reactivity to MUC1 glycopeptides by capture ELISA, as described in the later sections, and then hybridomas were cloned by limiting dilution. Antibodies purified by protein A affinity chromatography (Bio-Rad, Hercules, CA) were used for the detailed characterization of anti-MUC1 monoclonal antibodies (1B2 and 12D10). The isotype of monoclonal antibodies was determined using a Mouse Immunoglobulin Isotyping ELISA Kit (BD Biosciences, San Jose, CA).

Assessment of the Binding Activity of Developed Antibodies to MUC1 Glycopeptides. Anti-mouse immunoglobulin G (IgG) (Shibayagi, Japan) was diluted $(10 \mu \mathrm{g} / \mathrm{mL})$ into $50 \mathrm{mM}$ Tris $-\mathrm{HCl}(\mathrm{pH} 7.5)$, and $35 \mu \mathrm{L}$ of aliquots was added to each well of a 384-well MaxiSorp plate (Nunc, Waltham, MA) and incubated overnight at $4{ }^{\circ} \mathrm{C}$. After being washed, the plate was blocked with $90 \mu \mathrm{L}$ of Block-Ace (DS Pharma Biomedical, Japan) and incubated for $2 \mathrm{~h}$ at room temperature. Then, $15 \mu \mathrm{L}$ of anti-MUC1 antibodies was added and incubated for $3 \mathrm{~h}$ at room temperature. After being washed, $15 \mu \mathrm{L}$ of biotinylated peptides (0.01 ng, PDT*R-23ST-20-mer or PDT*R-STn-20-mer) and streptavidin-horseradish peroxidase (HRP, 2 ng, Thermo Fisher Scientific) was placed in each well of the plate and the plate incubated overnight at $4{ }^{\circ} \mathrm{C}$. After another wash, the plate was incubated with $25 \mu \mathrm{L}$ of 3,3',5,5' -tetramethylbenzidine (TMB) Plus-substrate-Chromogen (DAKO, Santa Clara, CA) as the substrate solution for HRP for $30 \mathrm{~min}$ at room temperature. The reaction was stopped by the addition of $25 \mu \mathrm{L}$ of $0.5 \mathrm{M}$ sulfuric acid, and the absorbance at $450 \mathrm{~nm}$ was determined using an EnVision Multilabel plate reader (PerkinElmer, Waltham, MA).

Assessment of the Specificity of Developed Antibodies Using Competitive Inhibition ELISA. Anti-mouse IgG 
(Shibayagi) was diluted $(10 \mu \mathrm{g} / \mathrm{mL})$ into $50 \mathrm{mM}$ Tris $-\mathrm{HCl}$ $(\mathrm{pH} 7.5)$, and $35 \mu \mathrm{L}$ of aliquots was added to each well of a 384-well MaxiSorp plate (Nunc) and incubated overnight at 4 ${ }^{\circ} \mathrm{C}$. After being washed, the plate was blocked with $90 \mu \mathrm{L}$ of Block-Ace (DS Pharma Biomedical) and incubated for $2 \mathrm{~h}$ at room temperature. Then, $15 \mu \mathrm{L}$ of anti-MUC1 antibodies was added and incubated for $3 \mathrm{~h}$ at room temperature. After being washed, $15 \mu \mathrm{L}$ of biotinylated peptide (0.01 ng, PDT*R-23ST20-mer or PDT*R-STn-20-mer), competitor (MUC1 glycopeptides), and streptavidin-horseradish peroxidase ( $2 \mathrm{ng}$ ) was added and incubated overnight at $4{ }^{\circ} \mathrm{C}$. After another wash, the plate was incubated with $25 \mu \mathrm{L}$ of TMB Plus-substrateChromogen (DAKO) as the substrate solution for HRP for 30 $\mathrm{min}$ at room temperature. The reaction was stopped by the addition of $25 \mu \mathrm{L}$ of $0.5 \mathrm{M}$ sulfuric acid, and the absorbance at $450 \mathrm{~nm}$ was determined by an EnVision Multilabel plate reader (PerkinElmer).

Assessment of the Binding Affinity of Anti-MUC1 Antibodies. The binding affinity of anti-MUC1 antibodies was measured with a Biacore T100 surface plasmon resonance instrument (GE Healthcare, England) and is expressed as the equilibrium constant $\left(K_{\mathrm{D}}\right)$. Biotinylated MUC1 glycopeptide (PDT*R-23ST-100-mer or PDT*R-STn-100-mer) or the biotinylated native MUC1 fraction was immobilized on an SA chip (GE Healthcare). Anti-MUC1 antibodies were injected over the MUC1 glycopeptide- or native MUC1 fractionimmobilized surfaces. Three kinetic parameters, the association rate constant $\left(k_{\mathrm{a}}\right)$, the dissociation rate constant $\left(k_{\mathrm{d}}\right)$, and the equilibrium dissociation constant $\left(K_{\mathrm{D}}\right)$, were obtained with BIAevaluation 3.1 software (GE Healthcare) using a bivalent binding model. The $K_{\mathrm{D}}$ value $\left(K_{\mathrm{D}}=k_{\mathrm{d}} / k_{\mathrm{a}}\right)$ was used to evaluate the binding affinity of the antibodies.

Evaluation of the Tandem-Repeat Dependence of Anti-MUC1 Antibodies. The tandem-repeat dependence of anti-MUC1 antibodies was analyzed by ELISA as described in later sections. Streptavidin (Thermo Fisher Scientific) was diluted $(10 \mu \mathrm{g} / \mathrm{mL})$ into $50 \mathrm{mM}$ Tris- $\mathrm{HCl}(\mathrm{pH} 7.5)$, and 35 $\mu \mathrm{L}$ of aliquots was added to each well of a 384-well MaxiSorp plate (Nunc) and incubated overnight at $4{ }^{\circ} \mathrm{C}$. After being washed, the plate was blocked with $90 \mu \mathrm{L}$ of Block-Ace (DS Pharma Biomedical) and incubated for $2 \mathrm{~h}$ at room temperature. Then, $15 \mu \mathrm{L}$ of biotinylated MUC1 glycopeptides (PDT*R-Tn-20-, 40-, 60-, 100-mer or PDT*R-SRn-20-, 40-, 60 -, 100-mer) was placed in each well of the plate and the plate was incubated overnight at $4{ }^{\circ} \mathrm{C}$. After being washed, $15 \mu \mathrm{L}$ of anti-MUC1 antibodies was added. After overnight incubation at $4{ }^{\circ} \mathrm{C}$, the plate was washed again, supplemented with $15 \mu \mathrm{L}$ of HRP-labeled anti-mouse IgG (GE Healthcare), and incubated for $2 \mathrm{~h}$ at room temperature. After a further wash, the plate was incubated with $25 \mu \mathrm{L}$ of TMB Plus-substrate-Chromogen (DAKO) as the substrate solution for HRP for $30 \mathrm{~min}$ at room temperature. The reaction was stopped by the addition of 0.5 $M$ sulfuric acid and the absorbance at $450 \mathrm{~nm}$ was determined using an EnVision Multilabel plate reader.

Quantification of MUC1 Protein in Cell Lines. The protein fraction of cell lines was extracted using Protein and RNA Extraction Kit for mammalian cells (Takara Bio, Japan), in accordance with the manufacturer's instructions. The quantification of MUC1 protein in the extracted protein fractions was determined using CA15-3 ELISA (Abcam).

Quantification of Transcript Levels of MUC1 and Glycosyltransferases in Cell Lines. RNA was extracted from the cell lines using Protein and RNA Extraction Kit for mammalian cells (Takara Bio), in accordance with the manufacturer's instructions. A reverse transcription reaction was carried out using SuperScript II Reverse Transcriptase (Thermo Fisher Scientific). Real-time quantitative PCR was implemented using the specific primers listed in Table $S 1$ and SYBR Premix Ex Taq II (Takara Bio) on an ABI 7500 Real Time PCR System (Thermo Fisher Scientific). The expression levels of glycosyltransferase and MUC1 were normalized against the housekeeping gene glyceraldehyde 3-phosphate dehydrogenase (GAPDH). The primers for GAPDH were from the Human Housekeeping Gene Primer Set (Takara Bio).

Flow Cytometry. Cells were grown in DMEM with 10\% FBS. After $48 \mathrm{~h}$ of growth, the cells were trypsinized and washed once in PBS containing $10 \%$ FBS. Cells $\left(1.0 \times 10^{6}\right)$ were resuspended in $200 \mu \mathrm{L}$ of anti-MUC1 antibody solutions. After $2 \mathrm{~h}$ of incubation on ice, the cells were incubated in 200 $\mu \mathrm{L}$ of fluorescein isothiocyanate-labeled anti-mouse IgG (Thermo Fisher Scientific) for $1 \mathrm{~h}$ on ice. After three washes, the cells were resuspended in $1 \mathrm{~mL}$ of PBS containing $10 \%$ FBS. The analysis was performed with FACS Aria (BD Biosciences), and flow cytometric data were analyzed using FlowJo software (TOMY Digital Biology, Japan).

\section{ASSOCIATED CONTENT}

\section{Supporting Information}

The Supporting Information is available free of charge on the ACS Publications website at DOI: 10.1021/acsomega.7b00708.

Primers for glycosyltransferases and MUC1 (Table S1); binding test of $12 \mathrm{D} 10$ to the glycopeptide (GVT*S-STn20-mer) (Figure S1); glycan specificity of anti-MUC1 antibodies assessed by competitive ELISA (Figure S2) (PDF)

\section{AUTHOR INFORMATION}

\section{Corresponding Author}

*E-mail: yoshito.numata@shionogi.co.jp. Tel: +81-6-63318404. Fax: +81-6-6331-8972.

ORCID ${ }^{\circ}$

Shin-Ichiro Nishimura: 0000-0002-6608-8418

Yoshito Numata: 0000-0002-0661-1983

\section{Author Contributions}

S.N. and Y.N. designed the experiments; S.N., T.T., J.O., and S.U. performed the experiments; N.O. provided new tools and reagents; S.N. and Y.N. wrote the manuscript; and S.N., H.T., S.Y., I.F., S.-I.N., and Y.N. made revisions to the manuscript.

Funding

This study was not supported by any financial grants.

Notes

The authors declare no competing financial interest.

\section{ACKNOWLEDGMENTS}

We wish to thank Akira Yamauchi for expert technical assistance and Keiko Kawamoto and Hirosato Kondo for their advice on this project.

\section{ABBREVIATIONS}

MUC1, mucin 1; mAb, monoclonal antibody; KLH, keyhole limpet hemocyanin; $\mathrm{TMB}, 3,3^{\prime}, 5,5^{\prime}$-tetramethylbenzidine; $\mathrm{IC}_{50}$, half-maximal inhibitory concentration; Tn, GalNAc $\alpha 1-O-S e r /$ Thr; T, Gal $\beta 1$-3GalNAc $\alpha 1-O-S e r / T h r ; 23 S T$, Neu5Ac $\alpha 2-$ $3 \mathrm{Gal} \beta 1$-3GalNAc $\alpha 1$-O-Ser/Thr; STn, Neu5Ac $\alpha 2-6 \mathrm{GalNAc} \alpha 1$ - 
O-Ser/Thr; 26ST, Gal $\beta 1$-3(Neu5Ac $\alpha 2-6)$ GalNAc $\alpha 1-O-S e r /$ Thr; dST, Neu5Ac $\alpha 2-3 \mathrm{Gal} \beta 1-3$ (Neu5Ac $\alpha 2-6)$ GalNAc $\alpha 1-O-$ Ser/Thr

\section{REFERENCES}

(1) Andrianifahanana, M.; Moniaux, N.; Batra, S. K. Regulation of mucin expression: Mechanistic aspects and implications for cancer and inflammatory diseases. Biochim. Biophys. Acta, Rev. Cancer 2006, 1765, 189-222.

(2) Taylor-Papadimitriou, J.; Burchell, J.; Miles, D. W.; Dalziel, M. MUC1 and cancer. Biochim. Biophys. Acta, Mol. Basis Dis. 1999, 1455, 301-313.

(3) Hanisch, F.-G.; Stadie, T. R. E.; Deutzmann, F.; Peter-Katalinic, J. MUC1 glycoforms in breast cancer cell line T47D as a model for carcinoma-associated alterations of O-glycosylation. Eur. J. Biochem. 1996, 236, 318-327.

(4) Storr, S. J.; Royle, L.; Chapman, C. J.; Hamid, U. M. A.; Robertson, J. F.; Murray, A.; Dwek, R. A.; Rudd, P. M. The O-linked glycosylation of secretory/shed MUC1 from an advanced breast cancer patient's serum. Glycobiology 2008, 18, 456-462.

(5) Lloyd, K. O.; Burchell, J.; Kudryashov, V.; Yin, B. W. T.; TaylorPapadimitriou, J. Comparison of O-linked carbohydrate chains in MUC-1 mucin from normal breast epithelial cell lines and breast carcinoma cell lines. Demonstration of simpler and fewer glycan chains in tumor cells. J. Biol. Chem. 1996, 271, 33325-33334.

(6) Müller, S.; Hanisch, F.-G. Recombinant MUC1 probe authentically reflects cell-specific $O$-glycosylation profiles of endogenous breast cancer mucin. High density and prevalent core 2-based glycosylation. J. Biol. Chem. 2002, 277, 26103-26112.

(7) Taylor-Papadimitriou, J.; Peterson, J. A.; Arklie, J.; Burchell, J.; Ceriani, R. L.; Bodmer, W. F. Monoclonal antibodies to epitheliumspecific components of the human milk fat globule membrane: Production and reaction with cells in culture. Int. J. Cancer 1981, 28, $17-21$.

(8) Danielczyk, A.; Stahn, R.; Faulstich, D.; Löffler, A.; Märten, A.; Karsten, U.; Goletz, S. PankoMab: a potent new generation antitumour MUC1 antibody. Cancer Immunol. Immunother. 2006, 55, 1337-1347.

(9) Ryuko, K.; Schol, D. J.; Snijdewint, F. G. M.; von MensdorffPouilly, S.; Poort-Keesom, R. J. J.; Karuntu-Wanamarta, Y. A.; Verstraeten, R. A.; Miyazaki, K.; Kenemans, P.; Hilgers, J. Characterization of a new MUC1 monoclonal antibody (VU-2-G7) directed to the glycosylated PDTR sequence of MUC1. Tumor Biol. 2000, 21, 197-210.

(10) Kohno, N.; Akiyama, M.; Kyoizumi, S.; Hakoda, M.; Kobuke, K.; Yamakido, M. Detection of soluble tumor-associated antigens in sera and effusions using novel monoclonal antibodies, KL-3 and KL-6, against lung adenocarcinoma. Jpn. J. Clin. Oncol. 1988, 18, 203-216.

(11) Ohyabu, N.; Hinou, H.; Matsushita, T.; Izumi, R.; Shimizu, H.; Kawamoto, K.; Numata, Y.; Togame, H.; Takemoto, H.; Kondo, H.; Nishimura, S.-I. An essential epitope of anti-MUC1 monoclonal antibody KL-6 revealed by focused glycopeptide library. J. Am. Chem. Soc. 2009, 131, 17102-17109.

(12) Tarp, M. A.; Sørensen, A. L.; Mandel, U.; Paulsen, H.; Burchell, J.; Taylor-Papadimitriou, J.; Clausen, H. Identification of a novel cancer-specific immunodominant glycopeptide epitope in the MUC1 tandem repeat. Glycobiology 2007, 17, 197-209.

(13) Oyelaran, O.; Gildersleeve, J. C. Glycan arrays: recent advances and future challenges. Curr. Opin. Chem. Biol. 2009, 13, 406-413.

(14) Manimala, J. C.; Roach, T. A.; Li, Z.; Gildersleeve, J. C. Highthroughput carbohydrate microarray profiling of 27 antibodies demonstrates widespread specificity problems. Glycobiology 2007, 17, $17 \mathrm{C}-23 \mathrm{C}$

(15) Matsushita, T.; Takada, W.; Igarashi, K.; Naruchi, K.; Miyoshi, R.; Garcia-Martin, F.; Amano, M.; Hinou, H.; Nishimura, S.-I. A straightforward protocol for the preparation of high performance microarray displaying synthetic MUC1 glycopeptides. Biochim. Biophys. Acta, Gen. Subj. 2014, 1840, 1105-1116.
(16) Blixt, O.; Lavrova, O. I.; Mazurov, D. V.; Cló, E.; Kracun, S. K.; Bovin, N. V.; Filatov, A. V. Analysis of Tn antigenicity with a panel of new IgM and IgG1 monoclonal antibodies raised against leukemic cells. Glycobiology 2012, 22, 529-542.

(17) Karsten, U.; Serttas, N.; Paulsen, H.; Danielczyk, A.; Goletz, S. Binding patterns of DTR-specific antibodies reveal a glycosylationconditioned tumor-specific epitope of the epithelial mucin (MUC1). Glycobiology 2004, 14, 681-692.

(18) Price, M. R.; Rye, P. D.; Petrakou, E.; Murray, A.; Brady, K.; Imai, S.; Haga, S.; Kiyozuka, Y.; Schol, D.; Meulenbroek, M. F. A.; Snijdewint, F. G. M.; von Mensdorff-Pouilly, S.; Verstraeten, R. A.; Kenemans, P.; Blockzjil, A.; Nilsson, N.; Nilsson, O.; Reddish, M.; Suresh, M. R.; Koganty, K.; Fortier, S.; Baronic, B.; Berg, A.; Longenecker, M. B.; Hilgers, J.; et al. Summary report on the ISOBM TD4 Workshop; Analysis of 56 monoclonal antibodies against the MUC1 mucin. Tumor Biol. 1998, 19, 1-20.

(19) Lo, C. Y.; Antonopoulos, A.; Gupta, R.; Qu, J.; Dell, A.; Haslam, S. M.; Neelamegham, S. Competition between core-2 GlcNActransferase and ST6GalNAc-transferase regulates the synthesis of the leukocyte selectin ligand on human P-selectin glycoprotein ligand-1. J. Biol. Chem. 2013, 288, 13974-13987.

(20) Wang, Y.; Ju, T.; Ding, X.; Xia, B.; Wang, W.; Xia, L.; He, M.; Cummings, R. D. Cosmc is an essential chaperone for correct protein O-glycosylation. Proc. Natl. Acad. Sci. U.S.A. 2010, 107, 9228-9233.

(21) Feizi, T.; Gooi, H. C.; Childs, R. A.; Picard, J. K.; Uemura, K.; Loomes, L. M.; Thorpe, S. J.; Hounsell, E. F. Tumour-associated and differentiation antigens on the carbohydrate moieties of mucin-type glycoproteins. Biochem. Soc. Trans. 1984, 12, 591-596.

(22) Higashi, K.; Asano, K.; Yagi, M.; Yamada, K.; Arakawa, T.; Ehashi, T.; Mori, T.; Sumida, K.; Kushida, M.; Ando, S.; Kinoshita, M.; Kakehi, K.; Tachibana, T.; Saito, K. Expression of the clustered Neu5Ac $\alpha 2-3 \mathrm{Gal} \beta O$-glycan determines the cell differentiation state of the cells. J. Biol. Chem. 2014, 289, 25833-25843.

(23) Feizi, T. Carbohydrate-mediated recognition systems in innate immunity. Immunol. Rev. 2000, 173, 79-88.

(24) Ajit, V.; Richard, D. C.; Jeffrey, D. E.; Hudson, H. F.; Pamela, S.; Carolyn, R. B.; Gerald, W. H.; Marilynn, E. E. Essentials of Glycobiology, 2nd ed.; Cold Spring Harbor Laboratory Press: Cold Spring Harbor, New York, 2009; Chapter 13.

(25) Brockhausen, I. Pathways of O-glycan biosynthesis in cancer cells. Biochim. Biophys. Acta, Gen. Subj. 1999, 1473, 67-95.

(26) Brockhausen, I. Mucin-type O-glycans in human colon and breast cancer: glycodynamics and functions. ЕMBO Rep. 2006, 7, 599-604.

(27) Hakomori, S. Aberrant glycosylation in cancer cell membranes as focused on glycolipids: overview and perspectives. Cancer Res. 1985, $45,2405-2414$.

(28) Shigeta, K.; Ito, Y.; Ogawa, T.; Kirihata, Y.; Hakomori, S.; Kannagi, R. Monoclonal antibodies directed to chemically synthesized lactogangliotetraosylceramide, a leukemia-associated antigen having a novel branching structure. J. Biol. Chem. 1987, 262, 1358-1362.

(29) Kurosaka, A.; Fukui, S.; Kitagawa, H.; Nakada, H.; Numata, Y.; Funakoshi, I.; Kawasaki, T.; Yamashina, I. Mucin-carbohydrate directed monoclonal antibody. FEBS Lett. 1987, 215, 137-139.

(30) Numata, Y.; Nakada, H.; Fukui, S.; Kitagawa, H.; Ozaki, K.; Inoue, M.; Kawasaki, T.; Funakoshi, I.; Yamashina, I. A monoclonal antibody directed to Tn antigen. Biochem. Biophys. Res. Commun. 1990, 170, 981-985.

(31) Kurosaka, A.; Kitagawa, H.; Fukui, S.; Numata, Y.; Nakada, H.; Funakoshi, I.; Kawasaki, T.; Ogawa, T.; Iijima, H.; Yamashina, I. A monoclonal antibody that recognizes a cluster of a disaccharide, NeuAc alpha(2-6)GalNAc, in mucin-type glycoproteins. J. Biol. Chem. 1998, 263, 8724-8726.

(32) Nakada, H.; Numata, Y.; Inoue, M.; Tanaka, N.; Kitagawa, H.; Funakoshi, I.; Fukui, S.; Yamashina, I. Elucidation of an essential structure recognized by an anti-GalNAc alpha-Ser(Thr) monoclonal antibody (MLS 128). J. Biol. Chem. 1991, 266, 12402-12405.

(33) Kjeldsen, T.; Clausen, H.; Hirohashi, S.; Ogawa, T.; Iijima, H.; Hakomori, S. Preparation and characterization of monoclonal 
antibodies directed to the tumor-associated O-linked sialosyl-2-6 alpha-N-acetylgalactosaminyl (sialosyl-Tn) epitope. Cancer Res. 1988, 48, 2214-2220.

(34) Fumoto, M.; Hinou, H.; Ohta, T.; Ito, T.; Yamada, K.; Takimoto, A.; Kondo, H.; Shimizu, H.; Inazu, T.; Nakahara, Y.; Nishimura, S.-I. Combinatorial synthesis of MUC1 glycopeptides: polymer blotting facilitates chemical and enzymatic synthesis of highly complicated mucin glycopeptides. J. Am. Chem. Soc. 2005, 127, 11804-11818.

(35) Rangappa, S.; Artigas, G.; Miyoshi, R.; Yokoi, Y.; Hayakawa, S.; Garcia-Martin, F.; Hinou, H.; Nishimura, S.-I. Effects of the multiple $\mathrm{O}$-glycosylation states on antibody recognition of the immunodominant motif in MUC1 extracellular tandem repeats. Med. Chem. Commun. 2016, 7, 1102-1122.

(36) Fiedler, W.; DeDosso, S.; Cresta, S.; Weidmann, J.; Tessari, A.; Salzberg, M.; Dietrich, B.; Baumeister, H.; Goletz, S.; Gianni, L.; Sessa, C. A phase I study of PankoMab-GEX, a humanised glyco-optimised monoclonal antibody to a novel tumour-specific MUC1 glycopeptide epitope in patients with advanced carcinomas. Eur. J. Cancer 2016, 63, $55-63$.

(37) Burchell, J.; Gendler, S.; Taylor-Papadimitriou, J.; Girling, A.; Lewis, A.; Millis, R.; Lamport, D. Development and characterization of breast cancer reactive monoclonal antibodies directed to the core protein of the human milk mucin. Cancer Res. 1987, 47, 5476-5482. (38) Burchell, J.; Taylor-Papadimitriou, J.; Boshell, M.; Gendler, S.; Duhig, T. A short sequence, within the amino acid tandem repeat of a cancer-associated mucin, contains immunodominant epitopes. Int. J. Cancer 1989, 44, 691-696.

(39) Dalziel, M.; Whitehouse, C.; McFarlane, I.; Brockhausen, I.; Gschmeissner, S.; Schwientek, T.; Clausen, H.; Burchell, J. M.; TaylorPapadimitriou, J. The relative activities of the C2GnT1 and ST3Gal-I glycosyltransferases determine $\mathrm{O}$-glycan structure and expression of a tumor-associated epitope on MUC1. J. Biol. Chem. 2001, 276, 1100711015 .

(40) Ohyabu, N.; Kakiya, K.; Yokoi, Y.; Hinou, H.; Nishimura, S.-I. Convergent solid-phase synthesis of macromolecular MUC1 models truly mimicking serum glycoprotein biomarkers of interstitial lung diseases. J. Am. Chem. Soc. 2016, 138, 8392-8395.

(41) Takeuchi, H.; Kato, K.; Denda-Nagai, K.; Hanisch, F.-G.; Clausen, H.; Irimura, T. The epitope recognized by the unique antiMUC1 monoclonal antibody MY.1E12 involves sialyl alpha 23galactosyl beta $1-3 \mathrm{~N}$-acetylgalactosaminide linked to a distinct threonine residue in the MUC1 tandem repeat. J. Immunol. Methods 2002, 270, 199-209.

(42) Brooks, C. L.; Schietinger, A.; Borisova, S. N.; Kufer, P.; Okon, M.; Hirama, T.; MacKenzie, C. R.; Wang, L.-X.; Schreiber, H.; Evans, S. V. Antibody recognition of a unique tumor-specific glycopeptide antigen. Proc. Natl. Acad. Sci. U.S.A. 2010, 107, 10056-10061.

(43) Borgert, A.; Heimburg-Molinaro, J.; Song, X.; Lasanajak, Y.; Ju, T.; Liu, M.; Thompson, P.; Ragupathi, G.; Barany, G.; Smith, D. F.; Cummings, R. D.; Live, D. Deciphering structural elements of mucin glycoprotein recognition. ACS Chem. Biol. 2012, 7, 1031-1039.

(44) Sterner, E.; Flanagan, N.; Gildersleeve, J. C. Perspectives on anti-glycan antibodies gleaned from development of a community resource database. ACS Chem. Biol. 2016, 11, 1773-1783.

(45) Loureiro, L. R.; Carrascal, M. A.; Barbas, A.; Ramalho, J. S.; Novo, C.; Delannoy, P.; Videira, P. A. Challenges in antibody development against Tn and sialyl-Tn antigens. Biomolecules 2015, 5, $1783-1809$.

(46) Persson, N.; Jansson, B.; Stuhr-Hansen, N.; Kovács, A.; Welinder, C.; Danielsson, L.; Blixt, O. A Combinatory AntibodyAntigen Microarray Assay for High-Content Screening of Single-Chain Fragment Variable Clones from Recombinant Libraries. PLoS One 2016, 11, No. e0168761. 